\title{
New AI-IP-EI Trilogy Opens Innovation to New Dimensions; Another Chip in "the Innovation Wall", What About Emotional Intelligence (EI)?
}

\author{
Serge Rebouillat ${ }^{*}$, Benoit Steffenino² ${ }^{2}$, Mirosława Lapray ${ }^{3}$, Antoine Rebouillat ${ }^{4}$ \\ ${ }^{1}$ STEPI'nd Arc Lémanique, Echenevex, France \\ ${ }^{2}$ DuPont International, Geneva, Switzerland \\ ${ }^{3}$ IP Expertise DPhil (Oxford UK), Pully, Switzerland \\ ${ }^{4}$ Rugby Academy Oyonnax, Nyon, Switzerland \\ Email:*sergereb@yahoo.com
}

How to cite this paper: Rebouillat, S., Steffenino, B., Lapray, M. and Rebouillat, A. (2020) New AI-IP-EI Trilogy Opens Innovation to New Dimensions; Another Chip in "the Innovation Wall", What About Emotional Intelligence (EI)? Intelligent Information Management, 12, 131-182. https://doi.org/10.4236/iim.2020.124010

Received: June 16, 2020

Accepted: July 27, 2020

Published: July 30, 2020

Copyright $\odot 2020$ by author(s) and Scientific Research Publishing Inc. This work is licensed under the Creative Commons Attribution International License (CC BY 4.0).

http://creativecommons.org/licenses/by/4.0/

(c) (i) Open Access

\begin{abstract}
The red thread of the AI-IP-EI Trilogy fate of this study, may have the appearance of a pot-pourri of intellectual and intelligence natures, as a matter of fact that it emanates from the genesis and practical synergism of the trilogy components. Concretely: The paper goes from: AI (Artificial Intelligence)-to the related IP (Intellectual Property) domain-to the relevance of EI (Emotional Intelligence); thus, forming the new AI-IP-EI Trilogy and its attributes and specific impacts to the new innovation process, and business model dimensions. These impacts are outlined and illustrated in part in essays of specific sections and all along. Several concrete study cases are used in the various dedicated sections; such as cases respective to the inventor status, and the EI factor, to the sport education innovative dimension, as well as to biases as inevitably promoting and revealing, to drastically enlarge open innovation supported by constructivism and creations of musical group as a model of open reflexive education. Overall resulting adapted business models appear to have a massive potential, and a multidimensional reach with a necessary attention to the IP policy on going definition. The durable green dimension is exemplified as well. The Ethics-plus, “@LEAST@”, said corpus is proposed. Could a human centric, AI-adapted-IP policy, internationally embraced, take part to some level of arbitrage, normative and enduring reliability in the field of interest? This seems to be "en route". Shall the EI (Emotional Intelligence) factor be supervised? Likely so. Is traditional open innovation renewed to a more comprehensive, more inclusive dimension reminding best business
\end{abstract}


practice and now "beyond"? Definitely, and will remain an opportunity, all along the 4IR quantum game changer to come. Neither seeking an in-depth expert analysis, nor a grand public over-simplified bavardage, of the trilogy, AI-IP-EI, four authors here propose an illustrated view of scientific, educational, visionary, demonstrative value to the subject matter. They are aged about 30-40-50-60, being IP \& Innovation strategist, future IP lawyer, children-teacher and professional academy sport coach, illustrator and bio-advanced materials engineering "Fellow Scientist". With experience of large and smaller organizations, being involved innovators, inventors and private artists as well, they are sharing their "non-jargonized down-to-earth", forward looking views through a structured analysis of the trilogy using realistic examples and data from rather diverse specialized independent sources, biotechnology, nanomaterials, sport... New invention and inventorship is been "reconceptualized" at least from an "insighter or insider" viewpoint, and sport team approach more broadly revisited from its academy level to its commercial asset impact, via educational virtues and values. Music group constructivism enters the scene as well with its exemplary reflexivity and alterity valued for open innovation. Science is the prime lead. "Emotional intelligence, EI, is still an emerging area within AI" and beyond? A new open innovation scheme is taking place. This prompted our intention to further contribute to this matter. Is EI, the tree gently challenging the wind? Generated by AI and IP streams and scientific applications therewith? Naturally. Conclusions are encouraging the follow-up of promising orientations underlined by the AI-IP-EI Trilogy, favoring human centric feature adoptions.

\section{Keywords}

AI, Artificial, Intellectual Property, IP, Emotional Intelligence, EI, Ethics, Open Innovation, Invention, Bigger Data, Semantic, Constructivism, Sport, Rugby, Jazz, Education, Biotechnology, Nanotechnology

\section{Introduction}

"The Innovation Wall", Figure 1, is going through its fourth revolutionary industrial (4IR) building stage via Bigger Data and Artificial Intelligence (AI) vectors; such as "Another Chip in the Wall".

The implicit meaning of the famous lyrics' "Another Brick In the Wall" by Pink Floyd, 1979, endorses various emotions left to interpretation (2014 [1]). Nonetheless a flavor of mechanical harmonization of the time tends to agree with some resentment brought-in similarly today by AI and its ability for example to "digitize" emotional intelligence (EI), sometime regardless.

Some consensual streams seem to have established themselves at a rather steady state, active as a background flux; around concerns, questions, fears, issues, controversial data, ethics, security, hacking, privacy, data ownership, consent... however an immense opportunity is recognized. 


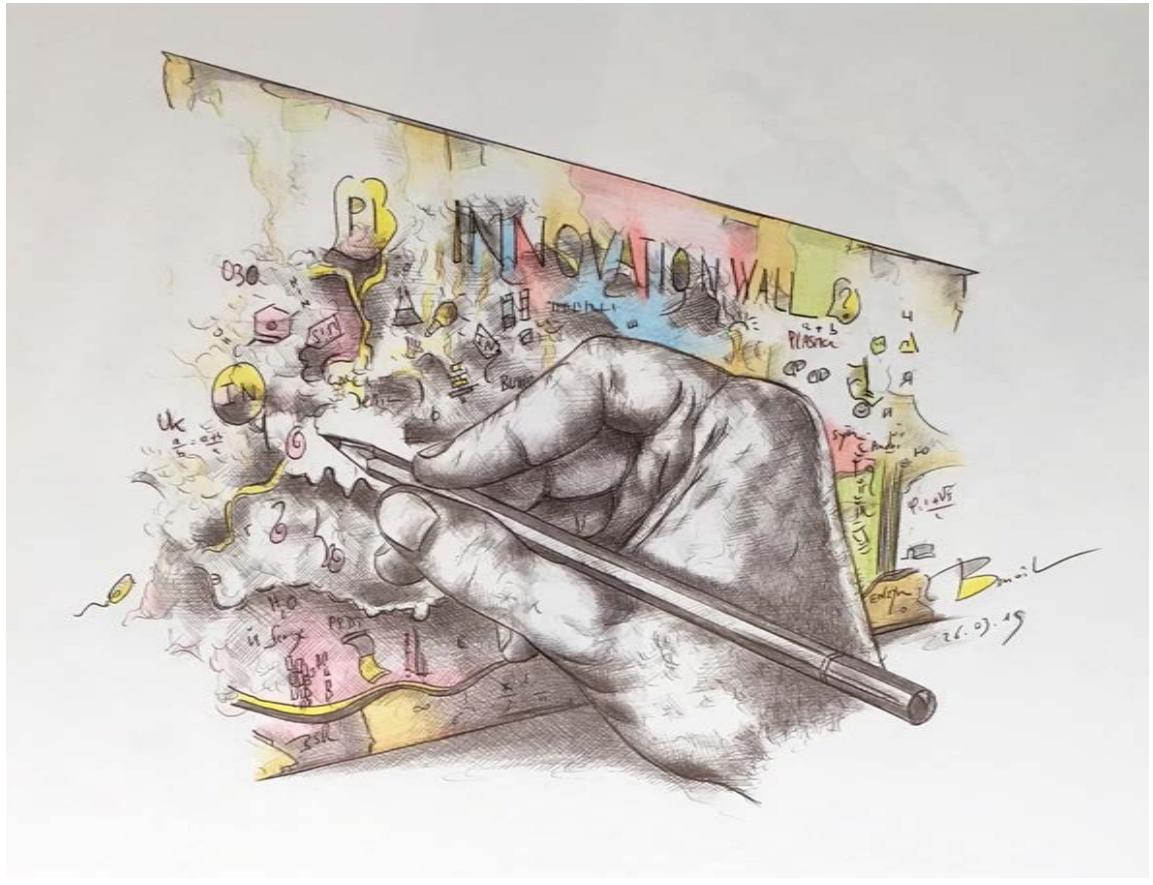

Figure 1. The Innovation Wall.

Bias, intrinsically anchored in AI founding algorithms and labeling practice, as well as relevant IP (Intellectual Property) data protection, their roots and evaluation, are subject to this highlighting and alerting done in an open and constructive manner. In this context "The Technology Trap" by Carl Benedict Frey, 2019, [2] coincidentally resonates stridently at the time of writing this article. Current viral pandemic, likely to be revealing a broadly anchored technology gap, cannot rest unmentioned either.

The author of this extended essay [2], p. XI cites W. Churchill who quipped that "The longer you can look back the farther you can look forward". With precaution and rational Toni Morrison in her address and reflection in "The Source of Self-Regard", 2019, [3] tends to keep distance from "notorious" references that may reduce both the author's and the reader's fresh imaginations. This is an authentic respect incentive for induced privacy.

Additive to the preceding quotes one may agree that the invention of the telescope raised far less anxiety than some other discovery technologies. Indeed, it brings closer faraway background details to help "visualize" and "comfort" the horizon.

The paper goes from: AI (Artificial Intelligence) in Section 2-to the related IP (Intellectual Property) domain in Section 3-to the relevance of EI (Emotional Intelligence) in Sections 4 and 8; thus forming the new AI-IP-EI Trilogy and its attributes in Section 5 with specific impacts, to the new innovation process, in Section 6, and business model dimensions, in Section 7. These impacts are outlined and illustrated in part in essays of Sections 9 and 10 and all along.

Several concrete study cases are used in the various dedicated sections; such as 
cases respective to the inventor status, and the EI factor in Section 9, to the sport education innovative dimension in Section 10, as well as to biases as inevitably promoting and revealing in Section 3, to drastically enlarge open innovation supported by constructivism and musical group' creations as a model of open reflexive education, in Section 6.

Overall resulting adapted business models appear to have a massive potential, a multidimensional reach with a necessary attention to the IP policy on going definition. The green durable dimension is also exemplified in Section 1. The Ethics-plus, “@LEAST๑”, proposed corpus in Section 5.

Conclusions, of section 11 are encouraging the follow-up of promising orientations underlined by the AI-IP-EI Trilogy, favoring human centric features adoptions.

\section{Further Introducing Remarks: Defining AI Remains an Evergreen Challenge}

Back in the decade 1984-1994, with applications of artificial intelligence (AI), (starting with expert systems), specialists try to redefine the rather academic and fuzzy environment of the AI, at the time still in its ivory tower semantic.

"Artificial Intelligence Applications in Chemistry" edited by T.H. Pierce and B. A. Horne, in 1985, [4] and about 10 years later, "Methods and Tools for Applied Artificial Intelligence" by D. Popovic, 1994 [5] clustered the AI definitions from selections of industrial applications and tools utilized to achieve the conceptual mapping and the programming of their assigned tasks.

The oversimplifying possibly escaping path, still used by some in 2017, cited by A. Jean, in her book "On the other side of the Machine. A scientist's journey to the land of algorithms.", 2019 [6], is to define AI simply as "non-natural" intelligence, which is either helpless and/or aggravates the non-progressing fact that intelligence, said natural, is still over-conceptually defined, due to its "nonmeasurable" factors and collateral influence.

Back in 1995, Popovic [5] cites the Webster dictionary of the time: Intelligence is "the ability to learn or understand or to deal with...". Underlining "the non-existence of a precise and comprehensive definition of (natural) intelligence itself... M. Lupu in 2017 [7], World Patent Information 53 (2018) A1-A3, cites definitions from 8 dictionaries. We reduce these dictionaries' definitions to the sentence starting fragment containing the first four-five keywords:

- the ability to learn, understand and think in a logical...

- the ability to learn, understand, and make judgments...

- the ability to learn or understand or to deal with...

- capacity for learning, reasoning, understanding...

- the ability to think, reason, and understand instead of...

- the ability to acquire, understand, and use knowledge...

- the ability to acquire and apply knowledge and skills...

- the ability to acquire and apply knowledge and skills... 
Remaining at the level of the definition of the word intelligence, meaning natural, one knows that the current trend is to define words by their contextual occurrence. Semantic analysis being a good mirror of the lexical environment of the selected word and a good tool to build commonly used word clouds, sometime animated, and associated with their corresponding ranking strength list.

"The dictionary of lexical fields presents all the words semantically related to the featured word, grouped by meaning and classified by relative strength. It illustrates the semantic proximity of the words" [8].

Using one of the commercial digital electronic dictionaries with an available lexical semantic field proximity search, we were able to translate the current semantic environment of the word intelligence.

It appears that this word has the following semantic proximity and strength:

- IQ is the first word in a list of 132 in terms of semantic proximity;

- Turing is the first author name in a list of 46 ;

- Artificial is the first adjective in a list of 10 ;

- Understand is the second verb in a list of 11.

It looks like that overall "intelligence" is at best at equal proportions defined by artificial intelligence environment words, including one of its well-recognized pioneer Alan Turing.

The animated-immobilized cloud representation of Figure 2 is a screenshot which captures the above at an infinitesimal moment in time.

Figure 2 is "almost" beneficial to the traditional paper dictionary definitions, which 8 of the 9 definitions reproduced above underlined the word understand in third or fourth position in the related definition extracts. All 9 definitions lack a "metric" assessment provided most predominantly by the word IQ in the semantic proximity analysis. IQ is designed to assess human intelligence. Thanks to AI, natural intelligence seems more completely defined possibly subject to a bias effect which will be one of our matter of interest.

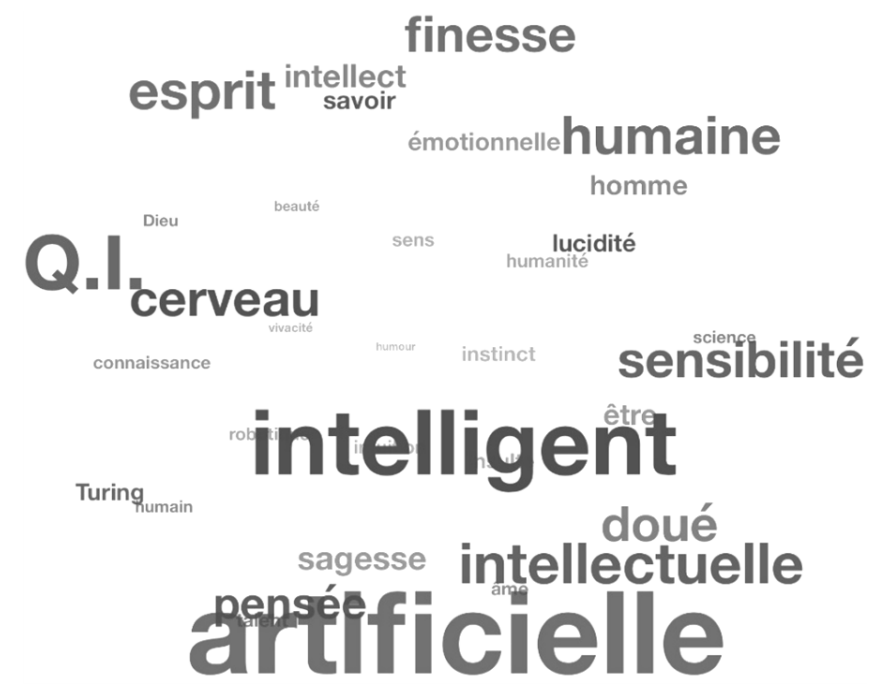

Figure 2. Intelligence defined by AI (in French vs Latin etymology). 
Let's recall that semantic analysis makes uses of logical, contextual and meaning relations between sentence component semantics, such as noun, verb, adjective, combined with the sentence semantics as a whole. The later can be part of cognitive, formal and structuralism approaches.

Latent Semantic Analysis (LSA) is a computerized mathematical technique for creating a word-document/row-column occurrence matrix and comparing derived vector-based representations of documents which are capturing their semantic content. Among applications such as data clustering, document classification and prior art, one ultimate function of LSA is then, using matrix derivation mathematics, to establish similarities and differences between sets of documents. Furthermore, the highlighting of the contextual environment occurs.

AI definition was adapted during its historical ups and downs: from the ivory tower, to the house of everyone as a vocal assistant via the expensive industrial machinery expert systems...

Here are chronological historical events associated with the AI quantum steps. It is majorly extracted, and slightly augmented, from p. 19 of WIPO Technology Trends 2019: Artificial Intelligence. Geneva: World Intellectual Property Organization [9] (as per suggested citing rule/original text being kept), otherwise inserts within the base WIPO list are referenced and indicated under quotes.

Such as from M. Lupu (World Patent Information [7]), which background of IR (information retrieval) and now extended to AI-IP is profusely proposed in much more details in further cited references.

“ $A$ short history-of Ar" [9]

"1936 Alan Turing demonstrates "that an ordinary computer could both process numbers and symbols" which is indispensable to AI." ("Methods and Tools for Applied Artificial Intelligence by Popovic" [5]). The Turing Machine was "born", an AI enabling precursor!

“1950 Alan Turing, in a paper, introduced the Turing's 'AI' test” [10].

"1954 Alan Turing died at 42. His death was classified as a suicide" [10].

1956 The term "artificial intelligence" is coined at a Dartmouth conference and AI is founded as an academic discipline. "Conference often cited as foundation event".

1956-1974 The golden years of AI enjoy government funding in promising, logic-based problem-solving approaches.

1974-1980 Overly high expectations coupled with the limited capacities of AI programs leads to the first "AI winter", with reduced funding and interest in AI research.

1980-1987 The rise of knowledge-based expert systems brings new successes and a change in the focus of research and funding toward this form of AI.

1987-1993 The second "AI winter" starts with the sudden collapse of the specialized hardware industry in 1987. The AI hype brings with it negative perceptions by governments and investors, as expert systems show their limitations and prove expensive to update and maintain. 
1993-2011 Optimism about AI returns and increases. New successes are marked with the help of increased computational power and AI becomes data-driven. In 1997, IBM's Deep Blue beats world champion Kasparov at chess. In 2002, Amazon uses automated systems to provide recommendations. In 2011, Apple releases Siri and IBM Watson beats two human champions at the TV quiz Jeopardy.

2012 - Today increased availability of data, connectedness and computational power allow for breakthroughs in machine learning, mainly in neural networks and deep learning, heralding a new era of increased funding and optimism about the AI potential. In 2012, Google driverless cars navigate autonomously and in 2016 Google AlphaGo beats a world champion in the complicated board game Go.

Disclosed funding in 2018 provides further insight into AI activity... representing about US\$46 billion in total (p. 35 [9]).

2019 EPO rejects proposal of AI Machine inventor name, i.e. a non-"naturalhuman" inventor name proposal in the autonomous DABUS application inventions. From 52 EU Experts [11]_"EU HLEG's Ethics Guidelines For Trustworthy AI".

After a glance at historical AI milestones of relevance to its current stage of evolution one can have a look at the institutions', European and international organizations, definitions to gain insights, sometime regulatory, policy as well as practical, into some of the boundaries of AI.

For example:

The 52 experts nominated by the EU Commission form a High-Level Expert Group on Artificial Intelligence [11], representing academia, civil society and industry. Their opinions were largely influencing, and therefore reflected in the AI definition below.

The IP5 offices, one authority group of reflection in terms of intellectual property (IP) provides as well some useful guidelines on AI.

The members of this group of 5, IP5 [12], are:

- the European Patent Office (EPO);

- the Japan Patent Office (JPO);

- the Korean Intellectual Property Office (KIPO);

- the National Intellectual Property Administration of the People's Republic of China (CNIPA);

- and the United States Patent and Trademark Office (USPTO).

EU group of 52 experts, HLEG, updated public definition April 2019 [13] adopted by EPO Munich March 2020 [14].

"Artificial intelligence (AI) systems are software (and possibly also hardware) systems designed by humans that, given a complex goal, act in the physical or digital dimension by perceiving their environment through data acquisition, interpreting the collected structured or unstructured data, reasoning on the knowledge, or processing the information, derived from this data and deciding the best action(s) to take to achieve the given goal. AI systems can either use sym- 
bolic rules or learn a numeric model, and they can also adapt their behavior by analyzing how the environment is affected by their previous actions".

WIPO [9] p. 19

"For the purposes of this report, AI systems are viewed primarily as learning systems; that is, machines that can become better at a task typically performed by humans with limited or no human intervention".

UNESCO adds to the above pool, in PARIS, on 21st March 2019 [15] (206 EX/42 Annex par. 2 p1).

While there is not one single definition of AI, it is commonly agreed upon that machines which are based on AI, or on "cognitive computing", are potentially capable of imitating or even exceeding human cognitive capacities, including sensing, language interaction, reasoning and analysis, problem solving, and even creativity. Moreover, such "intelligent machines" can demonstrate human-like learning capabilities with mechanisms of self-relation and self-correction, on the basis of algorithms that embody "machine learning" or even "deep learning", using "neural networks" that mimic the functioning of the human brain.

ISO (International Standards Organization) 2012

Artificial intelligence (AI): capacity of a functional unit to perform general functions related to human intelligence, such as reasoning and learning (source ISO 8373, 2012).

The above definitions complement each other's and tend to converge to define $\mathrm{AI}$ as the product of "learning machine via machine learning" and reciprocally or vice versa... a provocative deduction of the main author of this paper.

Figure 3 is a representation using extracts of the WIPO Pearl concept cloud and map which are "suggested relationships between concepts not yet linked to other concepts in a specific area of scientific or technical knowledge. The suggestions are made by a machine learning algorithm trained on the corpus of validated contexts and concept relationships in WIPO Pearl" [16].

The word "artificial intelligence" has been used in that specific case, therefore yielding additional supporting conceptual elements of a current definition of AI.

"The WIPO PEARL database now contains 178,000 patent terms, all validated by WIPO-PCT language experts" [16].

AI appears more and more as a general-purpose technology, which some contours still have to be sufficiently stretched beyond its intrinsic functionalities and tasks.

To close this chapter on AI background and evolution with a practical note, we may cite the expert system application TOGA ${ }^{\circledR}$ which back in the mid $80^{\prime}$ 's hold promises to enhanced industrial security and ecological robustness therewith concerning electrical transformation [4] ("Artificial Intelligence Applications in Chemistry" pp. 25-29). At that time the cost for the insurance company when a transformer failed would amount "above a million dollars". Nowadays damages would largely exceed that amount given electrical supply blackouts, fire, ecological remediation and land rehabilitation. 


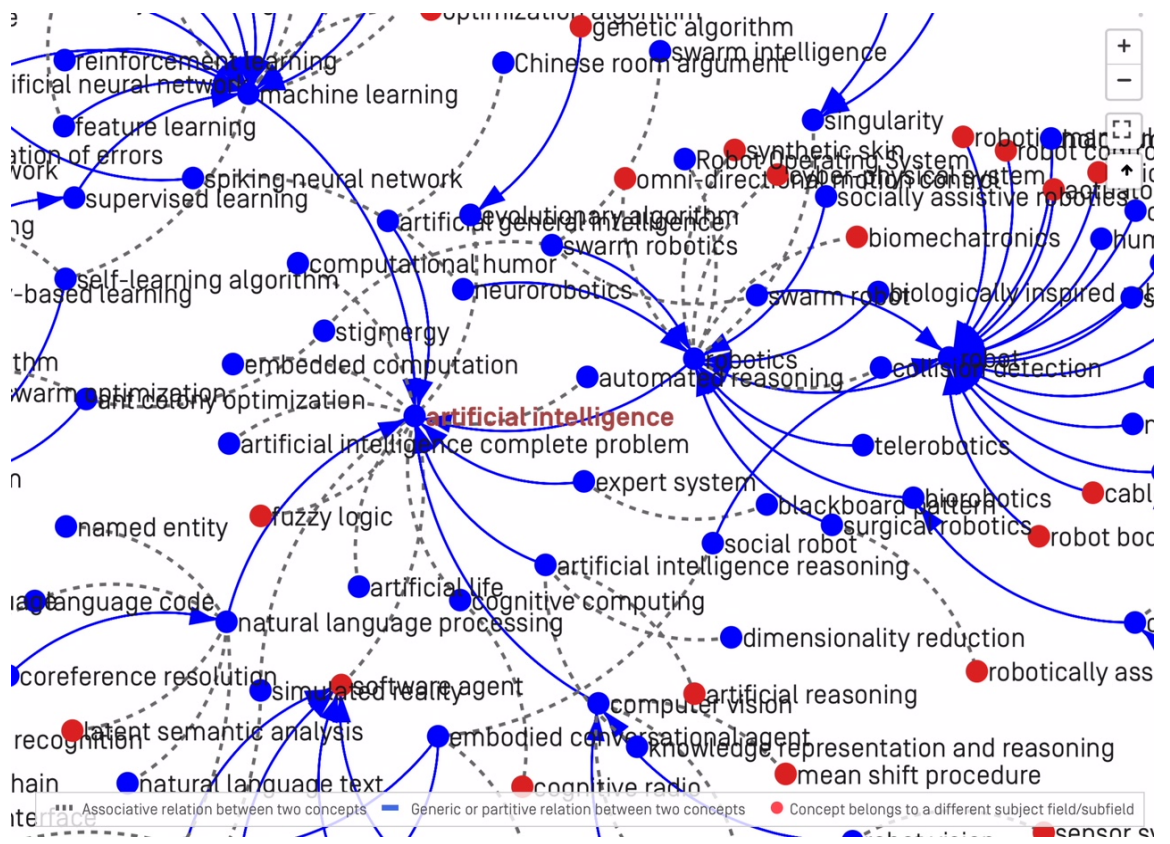

Figure 3. Pearl's view on EI [16].

In line early detection and diagnosis, based on chemical analysis of the insulation cooling oil combined with expert knowledge of transformer design, engineering, maintenance and related history, performed by the integrated expert system named TOGA", was rendered feasible; said "based on more than 20 years" of technical, scientific and heuristic best practice. This AI application was validated and further refined from a learning incremental process.

Recent innovation in transformer insulation and cooling, performed with insulating vegetable oil and insulating advanced laminates, is benefiting from such distributive expertise and automated decision-making processes. This with now more than 50 years of interrelated data associated with equipment of more than 30 years of life expectancy: e.g. Rebouillat, S. and Noirhomme, B. (2018), "OpenInnovation in the Electrical and Electronic Industries: Engineered Bio-Fluid Compositions Are Paving the Way, and Testing Therewith" [17]. Nanobiotechnology, biomaterials associated with smart materials, biopolymers and networks are part of this application [17].

It seems that human security and planet care could also be in the hands of AI destiny and its "imperious" mandate.

For education sake, AI straightforward patent search with lens.org open access search engine, then filtered with "bio" and separately with "nano", provides respectively $15 \%$ of the AI documents thus found, being bio-related and $5 \%$ being nano-related. These are noteworthy numbers given the broadness of the AI reach. More details on these data will follow. High discrepancy may be revealed as a function of the elected search approach. It can be minimized by bias interference reduction precautions that will be discussed on due course.

WIPO [9] indicates a $40 \%$ patent filing growth, in the field of life and medical 


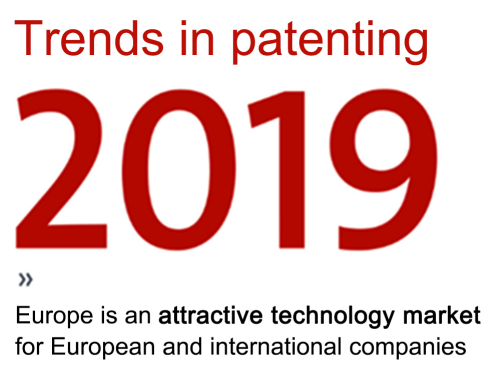

sciences, being part of the highest growth rates of AI industrial sectors, between 2013 and 2016. Bio and nanotechnologies have "a need to know". These relevant industrial sectors may have potential illustrative interest in our trilogy study, AI-IP-EI.

\section{AI to IP: Massive Potential, Multidimensional Impacting Reach, Far from a No-Brainer IP Policy}

\subsection{IP, a Guarded Resort for AI}

First focusing on patent global state in general, let's have a light-and-comparative overview using the IP5, EPO and WIPO available data. For calibration the IP5 together handles about 85 percent patent applications in the world.

The EPO PATENT INDEX 2019 infographic [18] Figure 4 with EPO copyright terms and conditions' permission [19] provides the key 2019 data on patent applications at the EPO office. With about 181,400 applications that year, the digital area is growing, by $10 \%$ in its computer technology. China applications at EPO are rising by $29 \%$, Korea by $14 \%$ and USA by $5 \%$. EPO handles $18 \%$ of applications for SMEs and individuals.
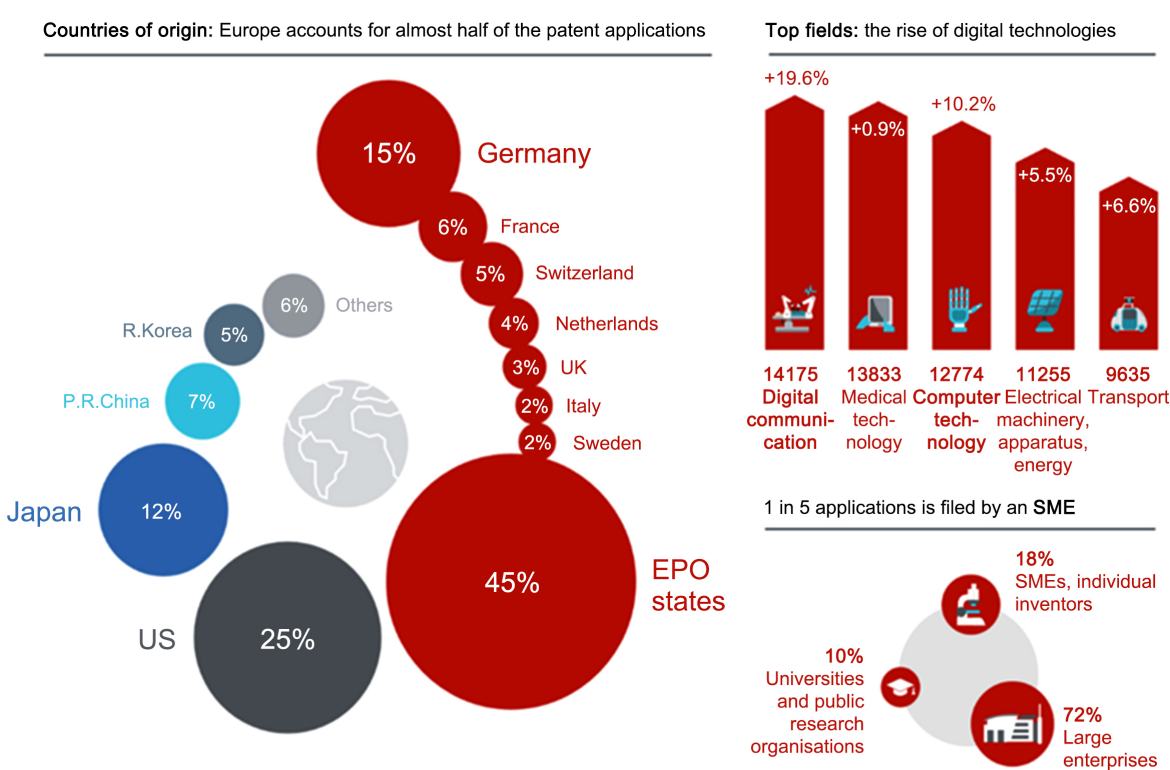

Patent applications at the European Patent Office continue to grow in 2019

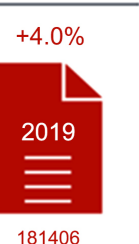

Other global growth champions

Top patent applicants
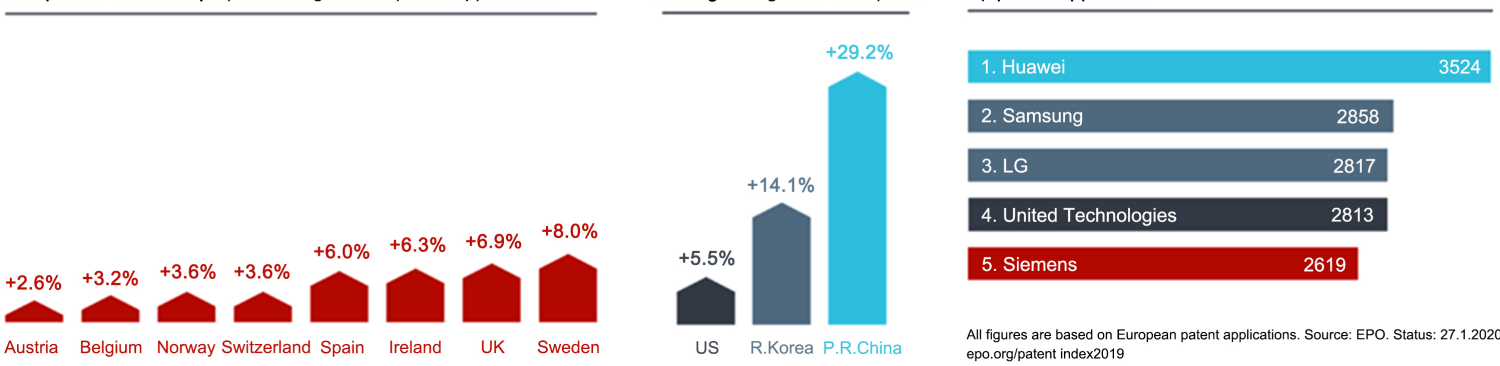
As described previously the IP5 offices, China, EPO, Japan, Korea, USA, receive about $85 \%$ of the world patent applications, representing in $2019,2.7 \mathrm{~m}$ (millions) applications [12].

As per WIPO IP facts and figures [20], in 2019 "China received approximately 1.54 million patent applications, which is $46.4 \%$ of the global total, which is similar in magnitude to the combined total of the next 10 offices" ranked by decreasing number of applications.

WIPO [9]: Here is our flash highlight summary, of this technology trend analysis of AI, reinforced by additional comments from [21] Fujii H. and S. Managi (2017) status and shifts with regard to artificial intelligence technology, AI, invention.

In a nutshell this effort provides with the essential data to figure out AI domains selection and IP landscape angle shots, regional developments, key actors, scientific publication occurrence and distribution, current and latent litigation, acquisition, IP policy with its own evolving complexity, some ethical and best practice considerations, governmental urgencies, innovation pooling necessity, future unfolding horizons.

As said before WIPO [9] indicates a 40\% patent filing growth, in the field of life and medical sciences, being part of the highest growth rates of AI industrial sectors, between 2013 and 2016. Other sector outstanding growth rates are provided too.

Figure 5 results of a demonstrative straight forward unfiltered patent search on "artificial intelligence" with lens.org open access search engine; an innovation knowledge databank. A sharp rise from 2010 onward from an approximate count of related documents of about 6000 to 37,000 in 2019.

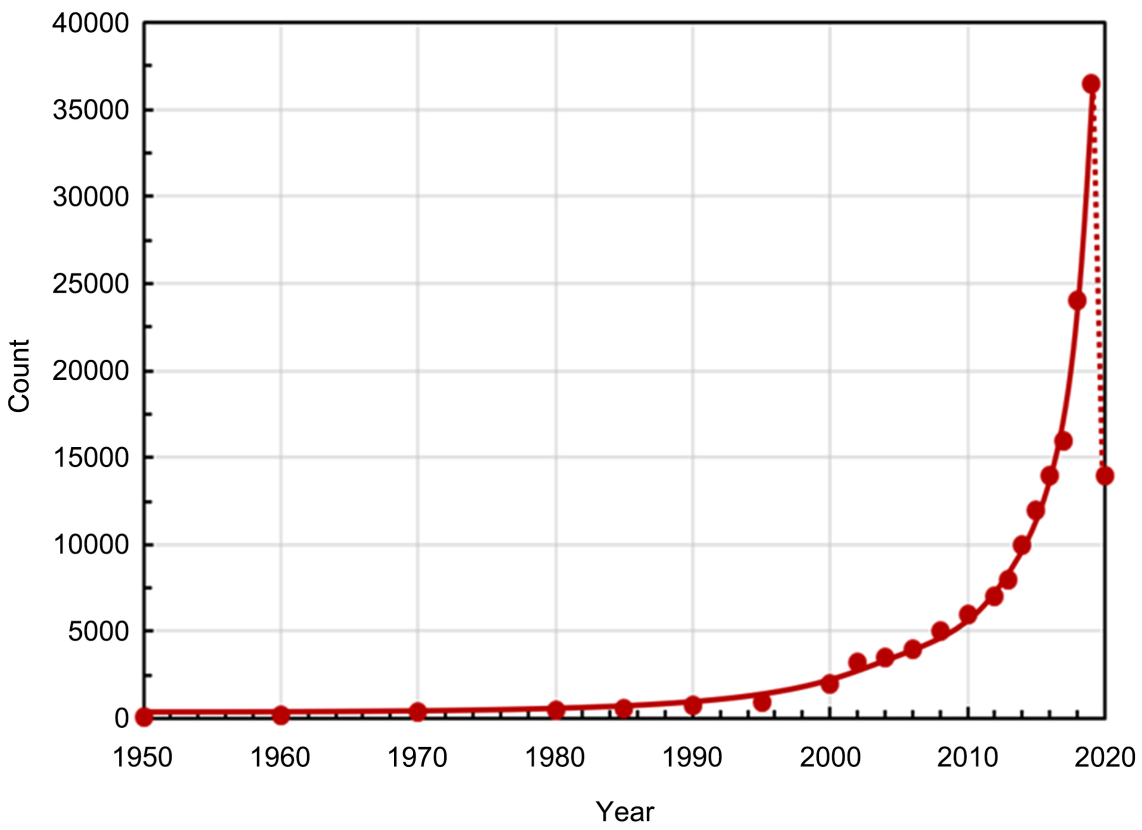

Figure 5. AI "patent document” count per publication year, AI. 


\subsection{AI in the IP Is a More Complex Search}

M. Lupu has established [7] [22] himself as the patent retrieval science expert and recently coordinated group studies related to AI and IP. He can elaborate on applicability and restrictions of IR techniques vs patent analysis, which we do not cover here.

S. Rebouillat, Lapray D. and M. [23], reviewed the domain of IP search methods(visualization-visuals-analytics-discovery), prompting out various forms of innovation (open, disruptive, inclusive, close, reverse, frugal, nested...) and the "all-in-one" IP-R\&D-business strategies model; all these topics are available online [23] at http://www.ijias.issr-journals.org/authid.php?id=509 and will be partially addressed later.

We have underlined before that AI definition is plural, subject to interpretation, evolving, part of a continuous newness trend and of a commoditizing towards rapid obsolescence; almost technology and industry agnostic.

In terms of IP analytics, unavoidably the trade-off between search precision and search recall is adversely unsolvable in time and sector interrelationships. Classification and analytic prediction become a "headache", a matter of choice and consistency therewith.

Therefore, methodology may vary from retrieval to retrieval pending on certain assumptions and pre-classifications [9] [22] more particularly in AI-IP field.

Illustratively, 6 large reviews, which represent close to some 1111 references, from S. Rebouillat, S. Ortega and F. Pla [24], (2013 to 2019), are carefully looked after as AI resourceful and inspirational; on-bio, nano, and smart materials-based methods, processes, products and resulting formulations. Their "bigger data" and innovation orientations enhance attractivity for AI.

Incidentally, raising the issue of commoditizing valuable knowhow, finely dispersed in lengthy method-claims of the AI-IP approaches. As an example, Rebouillat, Ortega \& Pla's 6 open access reviews cumulate more than 22500 downloads and more than 35000 consultations. All these topics are accessible online [24] at

https://www.scirp.org/journal/Articles.aspx?searchCode=Rebouillat\&searchField $=$ All\&page $=1 \&$ SKID $=59213665$.

The above AI IP search complexity leaves a wide-open space for bias which can be manually partially compensated for, at the expenses of time, cost and credibility. Not neglecting possibly more drastic effects on human and safety as well as traceability.

Opposite to valuable already cited analytic references, we have elected to avoid specific choices and classifications, with manual retouching, and decided to focus on areas of more straightforward concerns; "bias, transparency, accountability and privacy". Such as, to what extend human intrinsically creative mind can be integrated or discriminated by AI.

In short, we elect to put more interest to the AI-IP imperious links with innovation and emotional intelligence (EI). 
This is done, in a simple and accessible fashion, keeping in mind, the educational value and the constructive disruptiveness of the very nature of this illustrative study.

Let's first illustrate for example how EI may already cope with AI patent waves.

\subsection{Some Limited Data on IP \& AI-EI}

1) "Artificial Intelligence and Emotional Intelligence" used in a keyword search in a patent databank, ranks: Microsoft, Apple, Samsung, IBM, Amazon, Baidu part of the top 20 organizations.

2) "Artificial Intelligence and Emotional Intelligence" used in a semantic search in the same patent databank, ranks: LG, Samsung, IBM, Siemens, Huawei, Baidu part of the top 20 organizations.

3) "Artificial Intelligence and Emotional Intelligence" used in a keyword search, extended to forward and backward citations, in the same patent databank, ranks: Microsoft, IBM, Apple, Alphabet, Nuance Communications, Sony part of the top 20 organizations.

4) "Artificial Intelligence and Emotional Intelligence" used in a semantic search, extended to forward and backward citations, in the same patent databank, ranks: IBM, Microsoft, AT\&T, Apple, Alphabet, Siemens part of the top 20 organizations.

The integration of the forward and backward citations component of the search does not fundamentally changed the set of player categories regardless whether the search is based on a keyword Boolean string or a broader semantic search. This profile would rather fit a semi-open innovation pattern as we will illustrate later in the business section.

\subsection{Contextually}

The patent landscape, tends to be understood as the contextual clusters that make the environment of the given set of patents. In case 1 above, one can comment on the clusters deriving from a selection of that search. 1800 most relevant patents are part of the studied environment.

About 30\% remains in the artificial intelligence dominant cluster. 4 clusters maybe interpreted as to likely belong to the-emotional intelligence-part of the query string.

These are:

- Emotion identification;

- Emotional state;

- Facial expression;

- Speech recognition.

This group of 4 represents $13 \%$, of the 1800 patent sample, each, individually about $3.3 \%$.

Without drawing venturing conclusions, the emotional intelligence is present 
in the artificial intelligence patent waves.

A closer look at this group individual composition may be revealing.

\section{The EI Factor in the IP}

Emotional Intelligence (EI) emerged in the 1990's [25], with a related non patent literature (NPL) surge during the 2005-09 period followed by significant patent activity between 2010-19. Figure 6 is an illustration of AI/IE tandem.

Lens.org open access information retrieval engine was used to further "consolidate" this evolution of NPL compared to the patent activity. The results were obtained from a demonstrative straight forward unfiltered patent search on "emotional intelligence" with lens.org open access search engine; an innovation knowledge databank.

Figure 7(a) and Figure 7(b) illustrates that situation. Patent document count peak in Figure 7(a) represents a 4000 count of related documents. Scholarly works in Figure $7(\mathrm{~b})$ include, conference \& proceedings, papers, books, book chapters and the likes; with a peak at a count slightly above 5000 related works.

An extensive semantic patent search on EI provides some interesting results which an illustrative list of 25 patent titles is accessible in Table 1 . This is to underline the types of domain and interest which motivate such an IP protection necessity. Incidentally patent titles are secondary source of useful information which is often wrongly considered as non-regulated; WIPO provides some rules and guidelines to that effect, available at https://www.wipo.int/export/sites/www/standards/en/pdf/03-15-01.pdf [26].

The reading of these 25 titles is a noteworthy exercise. Possibly the impression of a balanced ratio of a healthy innovation activity, and concern areas may result.
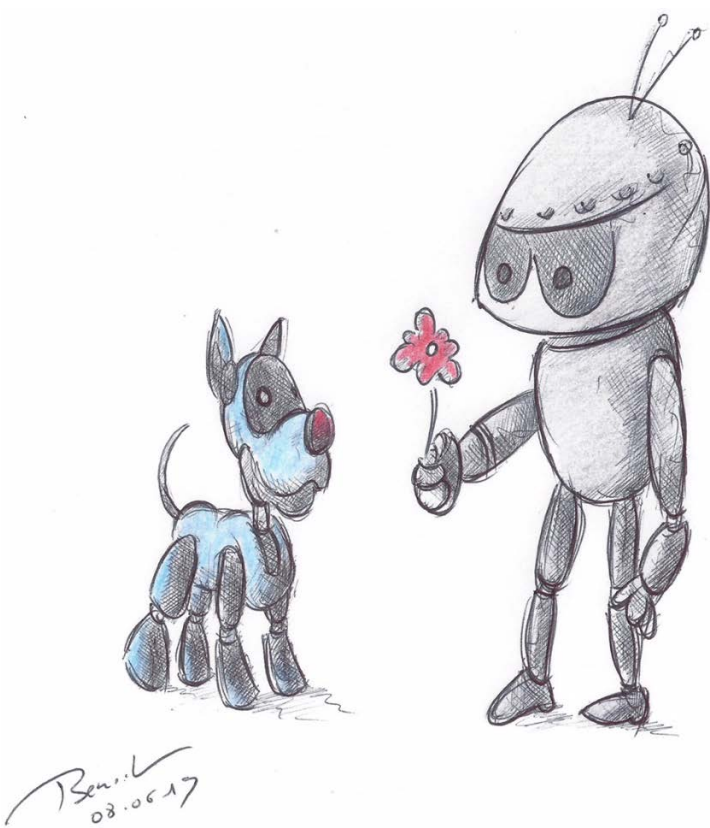

Figure 6. The Twins AI and EI, "without hurting your Feelings". 
Table 1. Patent title samples from semantic patent search on EI.

Method for providing service based on emotional intelligence index and device performing the same

Process for assessing and developing emotional intelligence in early childhood

Emotional intelligence quantification system and method through multi-level data convergence

A kind of child s Emotional Intelligence culture systems and cultural method

Emotion enlightenment device using brainwave

Method of teaching a foreign language by applying awareness and emotional intelligence tools

Method for determining emotional threshold and artificial intelligence device

Method and system for training for enhancing social intelligence

Evaluation method of social intelligence based on recognition and expression of emotion by facial action

Fully automated dermatoglyphics based multiple intelligence testing process leading to create an emotional social network and better online security and productivity application based integrated life management system

Emotional Quotient test program through musical items and method for executing the same

Emotional intelligence for a conversational chatbot

Methodology and computer system for gathering and analysing individual and collective emotional and intellectual intelligence

System for managing studying model of emotion-based and control method thereof

Potential emotional intelligence analysis system applied to individual psychology state-detection

Emotional intelligence engine for systems

Emotive intelligence applied in electronic devices and internet using emotion displacement quantification in pain and pleasure space

Methods and apparatus to enhance emotional intelligence using digital technology

Applied to the potential emotional intelligence analysis system device detected before particular job post

E.I.Q. tests (Emotional Intelligence Quotient Tests)

Potential emotional intelligence analysis system device applied to careers guidance

System to teach emotional competence

A kind of intelligence is dressed and is followed the trail of emotional affection clothing

System and method for the augmentation of emotional and social intelligence in technology mediated communication

System and method for detecting multiple-intelligence using information technology 


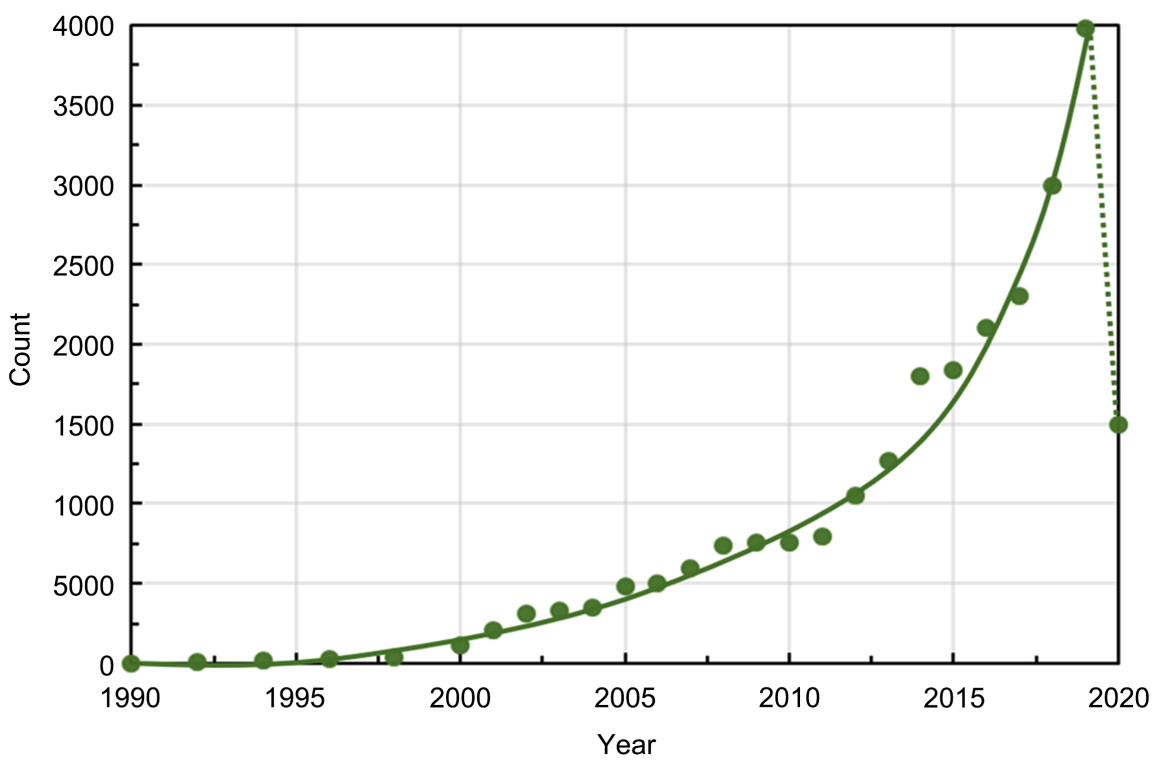

(a)

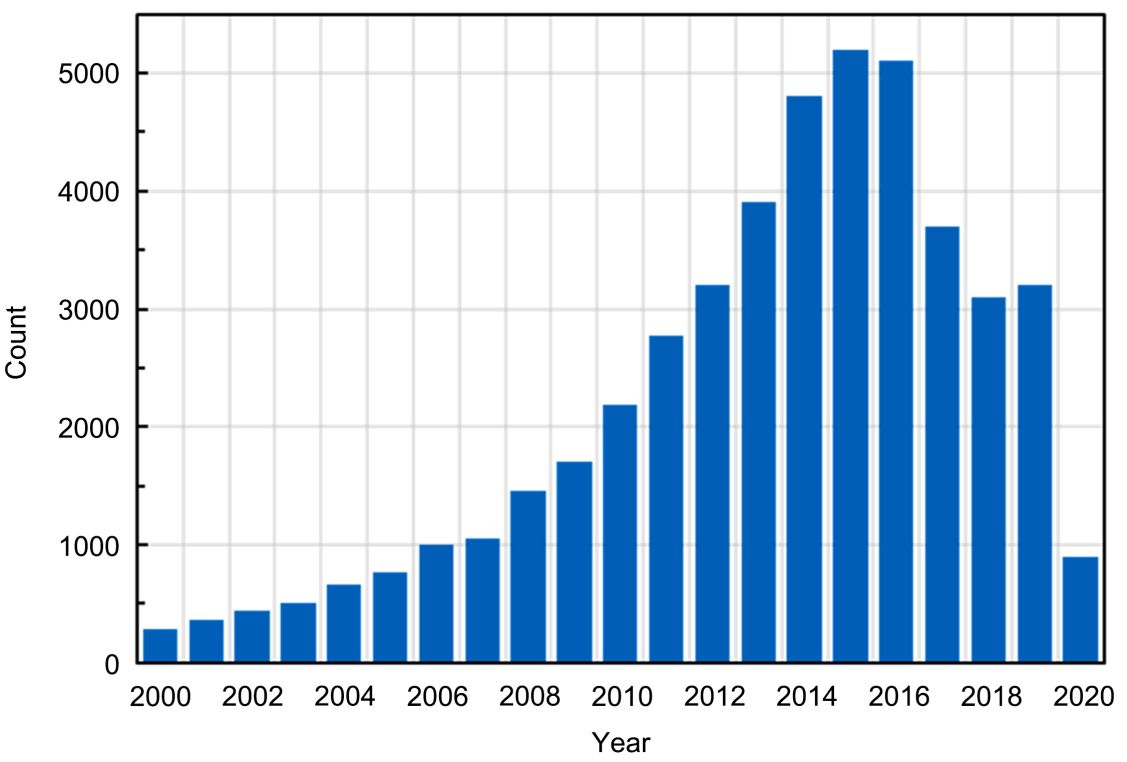

(b)

Figure 7. (a) EI "patent document" count per publication year; (b) EI "scholarly work" count per publication year.

This is reasonably expected and understandable in the current environment around technology human privacy impact and safety. Three keywords, "in bold font", per title help rapid reading.

Doing a WIPO Pearl search on "emotional" is directed to "emotion recognition" with a $4 / 4$ reliability score; this indicates the clear focus of this database [16].

A further clustering analysis of some 1021 EI related patents outlines that a bit less than $50 \%$ of this selected most relevant sample is attributable, at equal quart, to the following domains: 
- $\mathrm{EI}(1 / 4 \times 50 \%)$;

- AI (idem);

- Emotional State (idem);

- Task Performance (idem).

One could venture to over-conclude from this outcome, let's keep it for later.

\section{Biases Are Inevitable Promoters}

Rather than starting a philosophical debate on biases, one should probably let everyone's imagination and panorama further develop toward a more common vision spectrum and understanding of roles and responsibilities, of virtual compared to real appreciation, of strengths and weaknesses, of risks and opportunities; these being part of the 4IR, 4th Industrial Revolution, with its AI, IP, EI elements.

A limited list of the semantic environment of the word "bias" shall be a helpful introduction to the matter. The English word bias is mainly connoted with a sense of prejudice. "On The Other Side of The Machine", "De l'Autre Côté de la Machine" by A. Jean [6] is a very useful reference in the field of bias associated more specifically with AI algorithms. It has the "almost" pioneering merit to help reduce that connotation since the French word is apparently better balanced. An additional source of bias's "self-confident nature" published in 2011; “The Optimism Bias” by T. Sharot [27].

Here below is an extended, interpreted, augmented and provocative list of bias characteristics and related questions generally acknowledged in such references and in A. Jean's book in particular [6].

Some of them are IP, EI centric and derive from the authors' experiences in areas such as mathematical modeling [28], innovation, IP analytics and strategy, bigger data, data security, EI in science, business in general, education and sport. As well as direct exposure with primitive AI using very first generation of individual semi-portable ancestors, such as Oric Atmos, HP-41C and the 350 grams Sinclair ZX81 units of the 80's; and then more futuristic ones, later on naturally.

"Judgment and reasoning under uncertainty" appeared quite earlier-on in some university courses [29] and is now worth citing for the sake of updating and completeness and the fact that the proposed list below falls under this theme; bias semantic is indeed a matter of uncertainty and contextuality [30].

1) Bias can change reality in favor or against it.

2) Bias and "prophetic" or machine inventions?

3) Bias is implicit, explicit, induced...

4) Bias can be discriminatory/segregative.

5) Bias can result from machine learning \& deep learning.

6) Bias is part of the cognitive patrimony.

7) Bias can be virtual.

8) Bias further promotes scientific lucidity, scrutiny.

9) Bias propagates and spreads easily. 
10) Bias is inevitable.

11) Bias is unlimited.

12) Bias should be tracked down and disclosed.

13) Bias should promote a better virtual world awareness \& assessment.

14) Bias and passion/emotion are cogently associated.

15) Bias may derive from AI labeling.

16) Bias gets in between virtual and reality.

17) Bias should be reconsidered in IP policies.

18) Bias should be tested for IP validity.

19) Bias stigmatization shall not hinder innovation.

20) Bias should be detectable by AI accessible designed algorithms.

21) Bias should be integrated in IP rights ethical charter.

22) Bias self amplifies, denatures.

23) Bias should not be eradicated nor excessively sanitized.

24) Bias is part of a creative pattern.

25) Bias recognition can help reach consensus.

26) Bias can hinder IP validation.

27) Bias is part of intellectual categorization/labeling/segmentation.

28) Bias can be systemic/generalized.

29) Bias defies normal statistical distribution.

30) Bias comes from multiple/any sources.

31) Bias in complex modeling is hardly tangible/traceable.

32) Bias in AI/IP can be framed legally, monitored \& counseled.

33) Bias in robot can use $\&$ be an emotional (EI) factor.

34) Bias is part of immunity and self-protection.

35) Bias can be a derailing element.

36) Bias develops with extrapolation/lack of data.

37) Bias is sometime a visual artefact, perception, mirage, illusion.

38) Bias can help scientific mimicking.

39) Bias nurturing/nidation is part of poll surveys.

40) Bias has an extended ethnocentric connotation.

41) Bias is mathematically framed by numerical boundary conditions.

42) Bias in elementary IF/THEN/ELSE decision loop of AI programming?

43) Bias is not eliminated by isotropy/homogeneity/normalizing assumption.

44) Bias is everywhere, multidisciplinary.

45) Bias and model co-exist and can fit all?

46) Bias may give birth to an algorithmic linguistic semantic?

47) Bias image is "worth thousands of words".

48) Bias can grow exponentially towards rumors and social disorders.

49) Bias is likely not part of children (or more embryonic) nature readily.

50) Bias can be tactical such as in sport.

Figure 8 is an illustration of potential bias.

An illustration of a visualization bias is provided in Figure 9 from "A Review: 
On Smart Materials Based on Some Polysaccharides; within the Contextual Bigger Data, Insiders, 'Improvisation' and Said Artificial Intelligence Trends” by S. Rebouillat, F. Pla 2019 [31].

"No need to be a professional in the advertisement arena or a malicious developer, of fake impression carried by photography angle shot selections, to realize that the above triangles configurations of Figure 9, with bold solid heavy black sides, although linking the same matters, Composit(es)-Fiber(s)-Materi(als) \& (Polym(ers)) may, take different dimension depending on the persons observing these figures, their mindset of the time.

There is indeed an improvising dimension that may arise from bigger data analysis and visualization. Such as the representation on the left side may give a sharp and central dimension of the three first matters Composit(es)-Fiber(s)Materi(als)-(Polym(ers)), the middle representation may imply a massive central

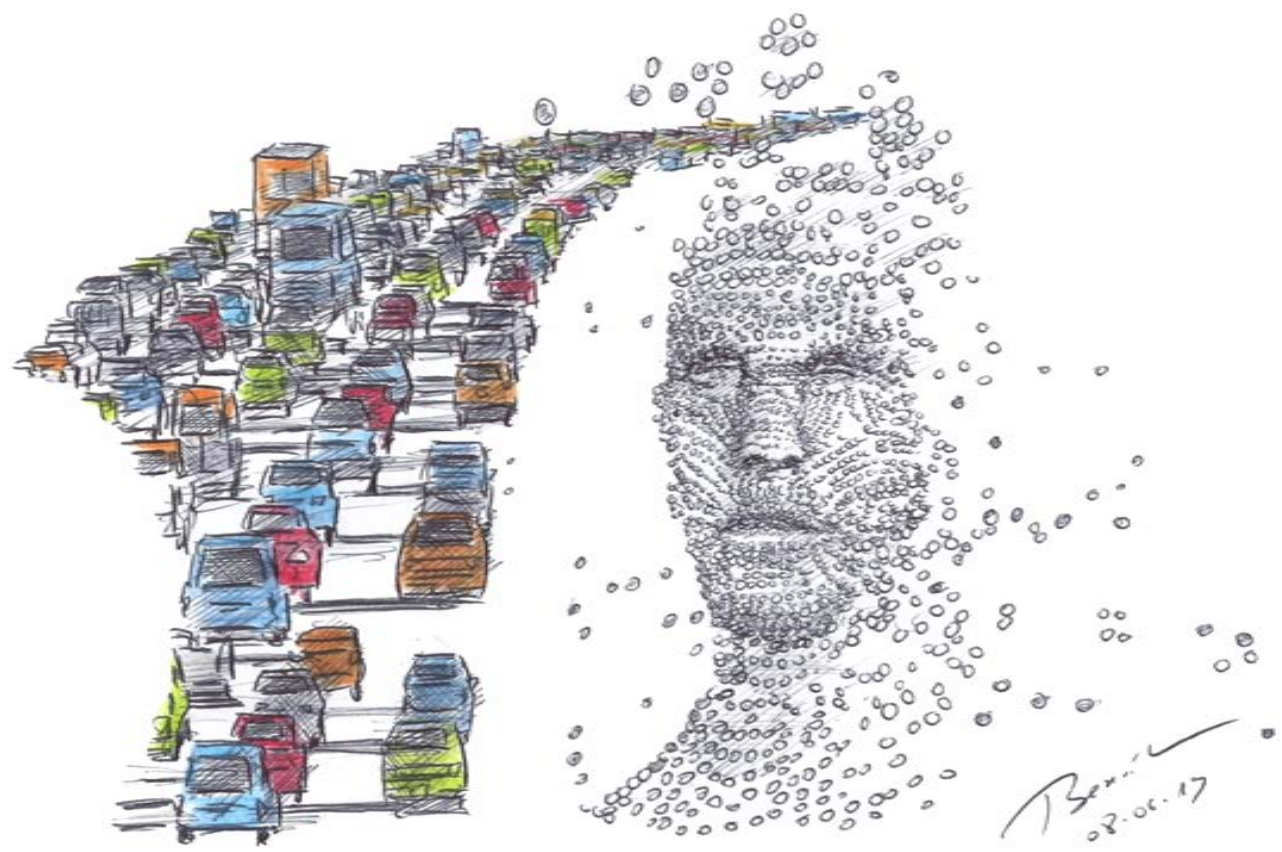

Figure 8. No bias, all going same direction, driverless; thanks artificial chip brain supervision.
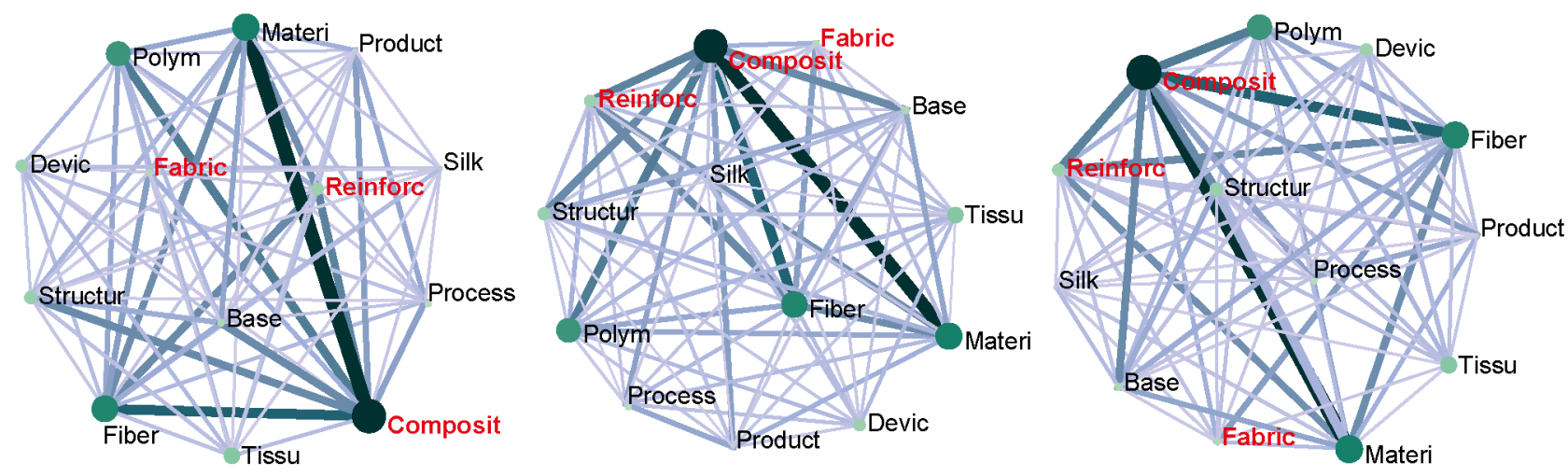

Figure 9. Visual bias. 
dimension of the four, and the representation on the right may suggest a sideway importance of the three first. Analogically the jazz player may improvise some mimics and positionings that will attract attention on some elements of his production and interactions.

\section{5. “@LEAST@”?-An Ethics Consensus}

\subsection{AI HLEG, IP5, EPO, UNESC0, WIPO, Public Contributions, IEEE, WEF}

Sufficiently previously stated, there is definitely an AI potential derailment price to pay for a sizable opportunity which is frameable via coherent, rather universal IP policies, sooner than later. Public contributors, users' poll surveys, representative expert task forces are interacting. These conversations are in good shape?

Let's the reader determine, whether these questions are also on a good track.

We are citing rigorously some main organizations, principally IP ones; in order to leave an objective debate open and to avoid any bias interpretation from our side.

Our opinion is provided too and limited to the extended author group which has left his position unchanged, untouched as it was instant-formulated prior to any examinations of any more formal positions of any origin. Thus, hopefully a valuable spontaneous virgin view point from the standpoint of representing the author extended group's authenticity and background, in the interest of a broader active or passive user target; with a less jargonized down to earth perspective at large.

\subsection{AI HLEG-The High-Level Expert Group on Artificial Intelligence (AI HLEG)}

This group of 52 experts, comprising representatives from academia, civil society, as well as industry, was already introduced earlier on, let's cite and quote them.

Their resulting document [32] was made public on April 8th 2019. The feedback of an open consultation from more than 500 contributors was integrated in a first draft, according to the final report.

Requirements of a trustworthy AI are provided on page 15 of the report [32] in Figure 2.

The key EU requirements for achieving trustworthy $\mathrm{AI}$ are:

- Human agency and oversight;

- Robustness and safety;

- Privacy and data governance;

- Transparency;

- Diversity, non-discrimination and fairness;

- Societal and environmental well-being;

- Accountability.

Here represented on our adapted dynamic rotary orbital design of Figure 10. 


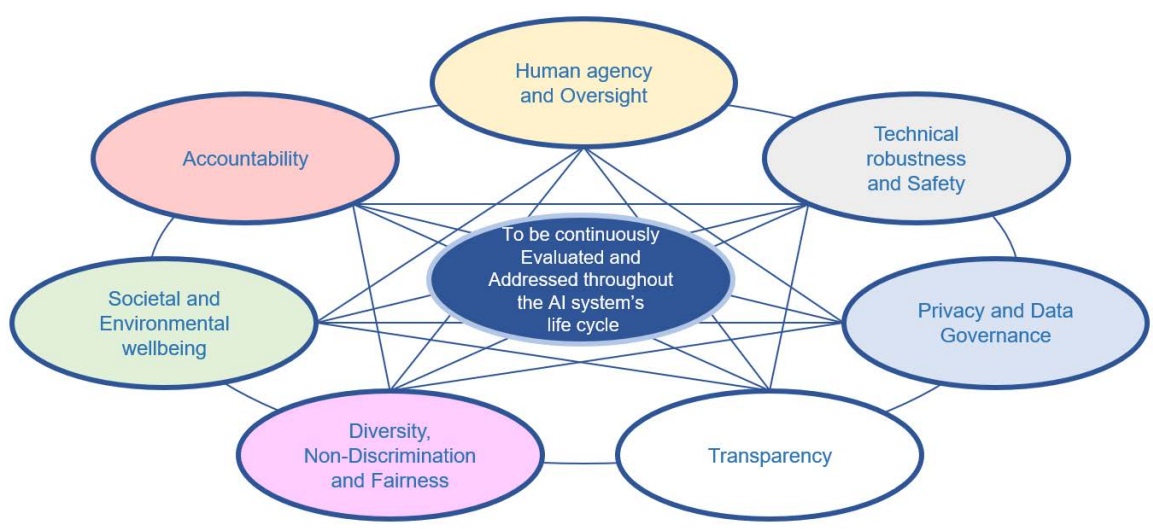

Figure 10. EU requirements for achieving a trustworthy AI.

In Figure 10 multiple relationships between the seven EU requirements, to be in place all along the life hood of the AI of interest. The author's design is made to imply dynamic orbital motion. Prime focus on a given requirement is variable pending on status and context, therefore the elliptic spots of the figure are meant to possibly change position.

The "EU guidelines on ethics in artificial intelligence: Context and implementation" appeared in September 2019 [33] reported as follows:

"Figure 2: Interrelationship of the seven requirements: all are of equal importance, support each other, and should be implemented and evaluated throughout the AI system's lifecycle".

\subsection{IP5}

Under permission of the hosting and collaborating entity, i.e. EPO's associated terms and conditions [19].

- "Report from the IP5 expert round table on artificial intelligence Munich, 31 October 2018" [34]:

In its introduction one notices.

"The present document-co-produced by Epo-IP5-outlines the main points discussed in the workshop with regard to Inventorship/Ownership, Patent Eligibility, Sufficiency of Disclosure and Inventive Step.

"Overall, the patent system seems to be adequately equipped to resolve issues relevant to the patenting of current AI technologies. However, a number of policy issues surrounding the rationale of the patent system, the application of patentability requirements and the interplay between patent protection and, for example, protection available for trade secrets, may need to be addressed in further detail. If AI technologies cease to be a mere tool for inventors and begin actively making decisions autonomously, the patent system may need to reconsider the development, ownership, transfer and exercise of rights".

At the "IP5 Heads of Office with IP5 Industry Meeting June 12, 2019" [35], it was further recognized that regarding the "Impact of AI and related New Tools on Harmonization": 
- Emerging technologies such as artificial intelligence (AI) and big data accessibility likely to have a substantial impact on upcoming "AI" patent and related IP practice and process;

- Already recognized by IP Offices and parties involved;

- New AI products for retrieval, writing, monitoring and analysis are already accessible.

\subsection{EPO}

One main ethics concern with the AI autonomously made inventions, is related to the naming of an inventor and the moral rights. The EPO made the news with the DABUS case [36] available online at:

https://www.epo.org/news-events/news/2020/20200128.html.

At this stage, to help put things in an international educational and illustrative prospective, i.e. the fact that inventor has to be a "natural" person, we encourage the reader to browse the grounds for EPO decision to strictly apply that policy to the two said DABUS cases.

Of particular broader international value, the EPO underlined that several national courts have ruled to the same human being aspect, that the European $\mathrm{Pa}$ tent Convention (EPC) is unambiguous and that the IP5 four other members, China, Japan, Korea and the USA embraces it as well. Additionally, EPO strikes the fact that no national law recognizes a machine, here said "a thing", as inventor. The case remains an application aspect; more about it in the EI essay.

Additionally, we shall consider that the works of the mind, which reflects the creativeness of the personality covered by the Berne Convention in article 6bis, are also protected as moral rights and could seem to "suffer" being insufficiently mentioned in the AI discussions. In the WIPO Technology Trends AI 19, 158 pages [9], a rather complete approach, the words "moral rights", combined, do not seem to appear.

Let's insist on the fact that the economic rights and the moral rights of the creator are separable thanks to the Berne Convention. Many national laws are aligned too.

Honor or reputation, or the right of integrity sometime described as such, and the motivation of the creators could possibly be "affected" when it's comes to over recognized AI role.

Finally, let's recon that Figure 1 is a piece of art wherein, similarly to some position of Toni Morrison [3] on Art, p. 389, the wholeness of the picture, equally so the elements of the work, leave full space and freedom to the observer to draw his own interpretation letting elements to speak out within and beyond the entireness of the creation. The works of the mind are refined matters viewed from these "inducing-mirror" angles.

For more, we refer the reader to "Understanding Copyright and Related Rights" [37] from WIPO 2016. Other useful references on the subject of moral and human rights linked to AI/IP are about "Governing AI" by C. Cath, 2018 [38], 
about "Algorithms and Human Rights" by the Council of Europe, 2017 [39], about "Rights to use Data" by H. Zech, 2016 [40], about "Exclusive Property vs. Access" by W. Kerber, 2016, [41] about "Data Collection and Data Markets at Age of Privacy", by B. Lorica, 2018, [42] and about "Ethical Priorities for Neurotechnologies" by R. Juste, 2017, [43] i.e. all within the last 4 years.

\subsection{UNESCO}

One may predominantly point out the UNESCO's position, on page 4 paragraph 10 of its preliminary study on the ethics of artificial intelligence (COMEST) [44], regarding this "absolute position" of no use of AI without human control in war conflict situations.

Additionally, its recommendation, still in the same study, towards algorithms and related AI components, such as self-training and decision-making matters, to be free of bias, is prominently representative of its human centric orientation to AI. Environmental crisis isn't neglected as well.

Let's underline that AI to IP and EI domains are closely associated to these preoccupations and many deriving applications. The risk and opportunity, including a balanced narrowing of technology gradients, are apprehended in this far more faceted study than covered here.

\subsection{WIPO}

WIPO, late 2019 launched a "Public Consultation on AI and IP Policy-Submissions [45], which encouraged internationally about 265 respondents [46] including member states, academic, scientific, private organizations, NGO, corporations as well as individuals.

AIIP WIPO Reference is made to the above acknowledged draft issues paper (the "Draft Paper") [45] prepared by the WIPO Secretariat which was made available for comments by all concerned parties.

I have submitted the spontaneous comments [47] in my own capacity, as creator and IP \& Innovation Expert. These comments are exclusively destined to represent my individual views on the pertinent issues of interest.

We as main author, volunteer one of our 7 comment sets [47] of the time destined to that call for inputs. Ahead of this writing it had been exposed to a group of relationships of about 12 individuals representing the type of profiles of the 4 authors-including two VPs-of the present work.

We let the reader appreciate the spontaneous, fresh, somehow inclined to a more naive and down to earth posture compared to truly specialized and "more engaged" opinions.

AI2IP Dr. Serge Rebouillat. Copyrighted comments 2020.

Identification should include:

Author and related information: Serge REBOUILLAT, associated alias extension STEPI'nd (“Science Technology Ethic Intellectual Property \& Related”); IP \& Innovation Strategist, ex-DuPONT. 
Comments:

A large part of the AI2IP WIPO draft refers to invention, creative works and designs in the rather new context of autonomous AI.

Numerical modelling was instrumental to AI, with a key difference in the end result validation; i.e. boundary conditions are used to test and surround the numerical modelling approach. The lack of convergence with the anticipated reality under given boundary conditions is a key rejection factor of the approach.

The AI autonomous creations, being any of the three previously mentioned, lack natural human efficient supervision once the liminary algorithm is established, generally by a natural human.

However, machine learning process and/or learning machine process are subject to biases induced by those processes' inherency and genesis.

Typically, a biased algorithm will preferably be abandoned than be corrected given the complex intrinsic and explicit intrication of biases. Furthermore, what about the safe disposal and potential catastrophic digital failure?

This raises one of the most fundamental ethical issues of autonomous AI, in particular with regard to IP rights at large.

This aspect is here treated as a penta-polar simplifying proposal towards improving the AI2IP WIPO draft.

Acronymized @LEAST@, it covers the ensuing specificities:

- L.: Legal;

- E.: Ethical, Equitable;

- A.: Advanced, Accountable, Accessible;

- S.: Safe, Secured;

- T.: Tolerable.

Should a legal person be associated "responsibly" to the inventors' tandem such as $\mathrm{AI}$ and at least one natural human coinventor or collaborative inventor as proposed earlier in my comment series?

Should AI-IP watchers be instituted as a group of AI-IP experts available at for example a WIPO level to assist applicants and examiners in the bias avoidance improvement? This preserves AI-IP ethic in general, creators moral rights recognition, patent incentivizing innovation, its validity, enforceability and infringement lowest rate...

Should a WIPO driven AI ethic charter be in place? One can usefully refer to the Canadian December 2018 initiative; easily "googled" under "The Montreal Declaration for the Responsible Development of Artificial Intelligence Launched".

Should one expect an advanced and accountable posture of IP institutions? Is keeping on top of the AI-IP aspects not a prime expectation of societies in general?

Should the cutting edge of AI-IP be led by IP leading institutions and supported by additional proportioned funds. 
IP rights in general have largely contributed to the global and ethical safety. The fact that an invention must be reproducible under its preferred mode at least, at the risk of not being granted or later invalidity, is a tremendous safety factor.

As covered in one of my previous comments should the examiner or ad hoc person interactive access to the AI machine and testing therewith be implemented with proper means?

Should the owner of the AI autonomous invention be accountable for keeping track of the AI invention generator during the patent validity? Which would strengthen enforceability, moral rights, infringement dissuasion and possibly limit the giant data accounting for the invention essential prior art...

Should a tolerable consensus be monitored and maintained?

Should WIPO mission or equivalent, on IP rights and access gap tolerability related factors, be asked for a follow up test of the AI IP technology access gap reduction?

Should a Consensus Interest Test be established? This would promote or demote eventual AI pressure and may favor research of consensus and innovation.

This is the "End" of comments AI2IP SR VII 220.

Figure 11 is an illustration of a dilemma.

\subsection{IEEE}

The IEEE Standards Association is also involved such as in the "Global Initiative on Ethics of Autonomous and Intelligent Systems" as reported publicly representing a normative established authority; online https://ethicsinaction.ieee.org/.

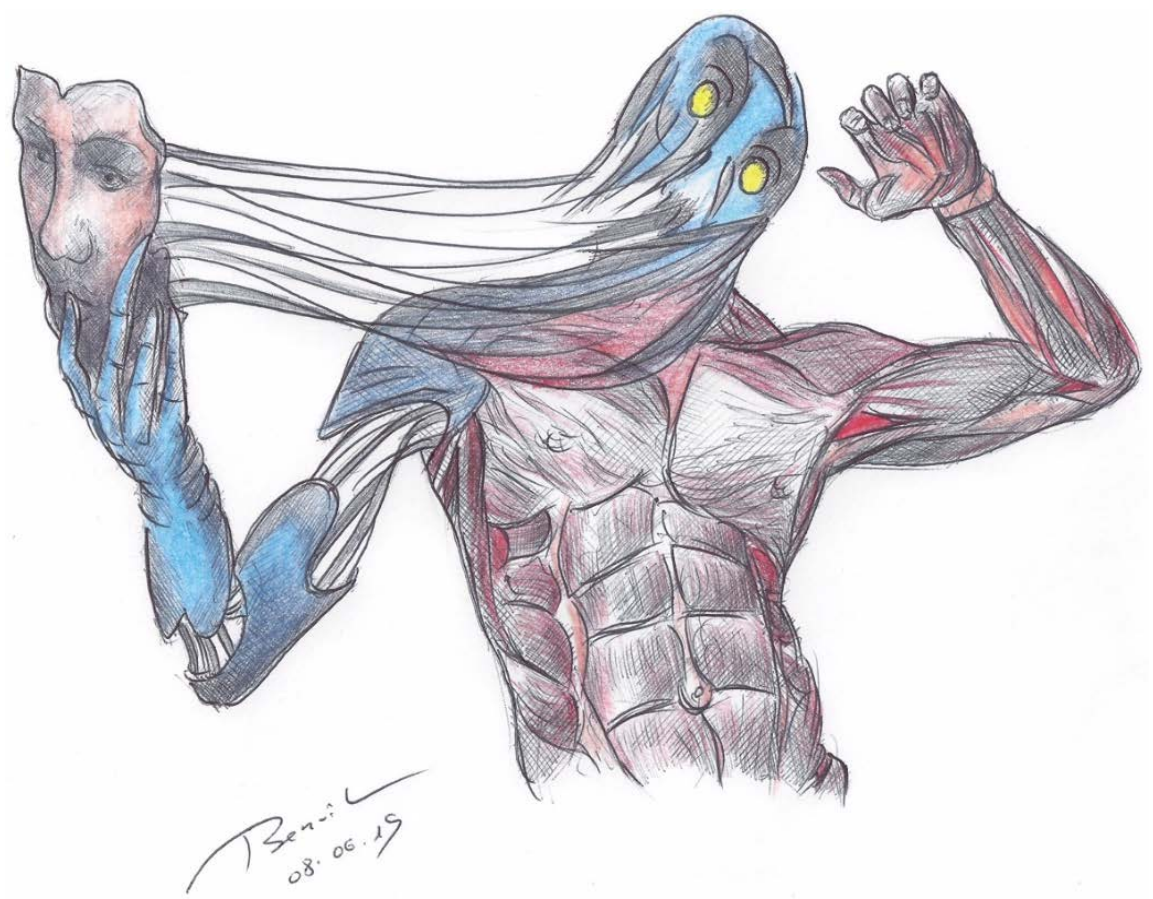

Figure 11. Are you an unplugged AI robot, or an EI human? 


\subsection{WEF-World Economic Forum}

Kay Firth-Butterfield, Head of AI and Machine Learning at the World Economic Forum (WEF), summarizes [9], pages 121-122, the "narrow AI" everyday impact with a pressed orientation of responsible human to responsible opportunity, saying that "these problems fall into four broad main categories; bias, transparency, accountability and privacy".

Those are good keywords, fitting well with this section of our propos on AI-IP-EI Trilogy. Her statement added to some crucial aspects of reputation and trust with brand's IP endangerment. This puts, back in place, the economy part in case of underestimated risks. "Artificial Intelligence Collides with Patent Law, 2018” [48] seems to be acknowledged as well. Indeed AI-IP-EI Trilogy may affect a number of legal schemas.

\section{6. "The Innovation Wall” Opens Innovation to New Dimensions}

Supported by Tony Morrison's anthology of "The Source of Self-Regard”, [3] p. 367, education regardless of its happening within a scholar tradition, a know how practical heritage, a background and experience foundations, a street phenomenon, globally or locally, follows an ageless learning going "randomly" from-data to information to knowledge to wisdom-in any order naturally.

Her sequence of the four just cited dimensions brings back the opportunity to an extended open innovation at the era of largely excessive data and information availability compared to human capacity on its own.

We may find this extrapolation, of a humanist sommité's remark, distant from its original context. Nonetheless her lifelong she has regarded ethno bias in a unique and profoundly reflected manner challenging the way this aspect was generally approached. Leaders' humility does influence as seen later with work of Owens.

Furthermore, her writing, [3] p. 376, on the jazz quasi universal phenomena, transcendentalizes usual bias and incite most, together to become part of its creations' mode regardless of the "stage" of education, priorly mentioned; consequently, promoting new nontraditional dimensions to open-innovation; constantly and freely reinvented.

Laterally and analogically, Figure 1 in mind, let's venture to outline that the squash energetic and defying sport is, sometime, said to be born in prison. It consists of making use of the walls to selectively spin back the ball such as Basque pelota, in a more open space, still against a wall; imagination performs.

Finally, one shall recon that Figure 1, "The Innovation Wall", is a piece of art. It shall leave to the observer the freedom of interpretation and imagination in its entirety, as well as within its elemental parts, letting them tell their own story, interrelationship and culture to the observer' specific imagination. This is a wide-open innovation new process. 
Figure 1, ever bigger data wall, relays our propos to new dimensions of open innovation validating previous contributions on the matter, which we selectively recite to be newly recontextualized. EI has a plenary role to play as well in this mutation.

\section{AI-IP\&EI}

\section{Still Business as usual? With a new open innovation dimension?}

Heuristic, constructivism, reflexivity, alterity, autonomisation, reasoning under uncertainty, play it, do it, be it; all these terms set the tone to adapt open innovation to the AI environment at minimized risk.

We have largely published on the innovation and bigger data matters, heuristically and more in-depth, associated with prime subjects of interest [23] [24], 2013 to 2019; here is a summary of the innovation premise which we established.

"The emotional intelligence has become a recognized essential part of a global 'balance', in this virtual-reality". Let's see what we said some, about, 20 years ago, on related skills [49].

"Can we foresee the profile of the next generation of scientists and engineers?

The people behind innovation are essential to establish the foundations of the future successful businesses. In the chemical industry, the chemist, the physicist, the material scientist, the engineers are playing an important role in the creative process which is required to follow the pace of change. New organizational concepts have been proposed in order to schematize the industry adaptation to this 'new' global environment. We found that most of them require from the people a balance of skills which we propose to abbreviate with the acronym $4 \mathrm{C}$, where the 4Cs represent: Connaissance, Creativity, Competence, Communication. 'Pursuing with', the bubble concept is one way of stimulating innovation. It is possible to combine enterprises or projects $\mathrm{A}, \mathrm{B}, \mathrm{C}$ in a way that the mentors, the promoters, the generators of the enterprise $\mathrm{A}$ have a chance to play another role in $\mathrm{B}$ or in C...”. Then $4 \mathrm{C}$ advanced to $4 \mathrm{C}^{2}$; $(2)$ adds the Collaborative adjective to each $4 \mathrm{C}$ dimension [23].

Figure 12 helps capture more about the above 4C innovative tetralogy. The number of current innovation styles, from open to close, disruptive, collaboratory ${ }^{\circledast}$, from reverse to inclusive, nested and frugal, are more or less self-explanatory terminologies and further enlightenment can be found, e.g. in Lapray et al. [50] [51], in reviews on the matter, [52] is covering some of them.

More literature on artistic creation and more expressly musical art is dedicated to the innovation traits of musical production, rather say improvisation; Jazz is of an established relevance.

Figure 13 attempts to provide the 4C's corresponding Jazz terms and concepts therewith developed by the expert Charles Calamel [53], in the creation, integration, self-learning and improvisation model that Jazz culture continues to develop spontaneously. One may further cite Charles Calamel proposed acronym "CRAC" [53], with stands for Competent, Responsible, Autonomous, Creative... 


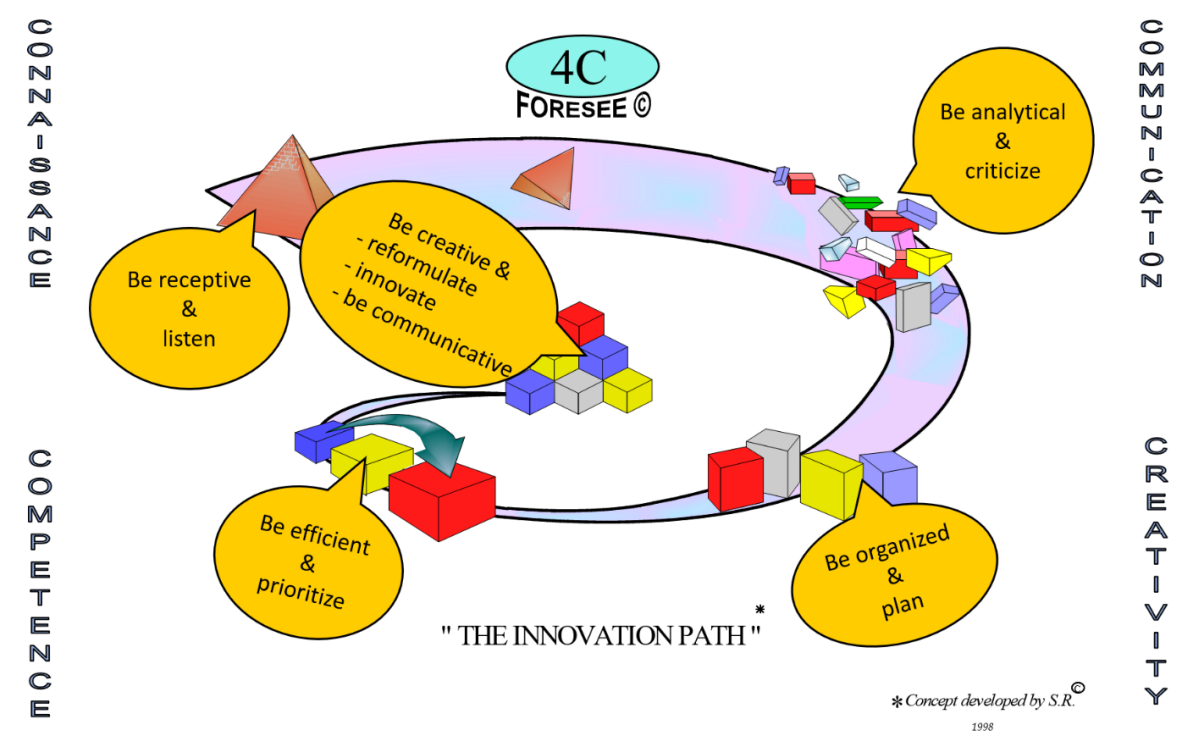

Figure 12. Foresee $4 \mathrm{C}-4 \mathrm{C}^{2}$, timeless, now AI trend.

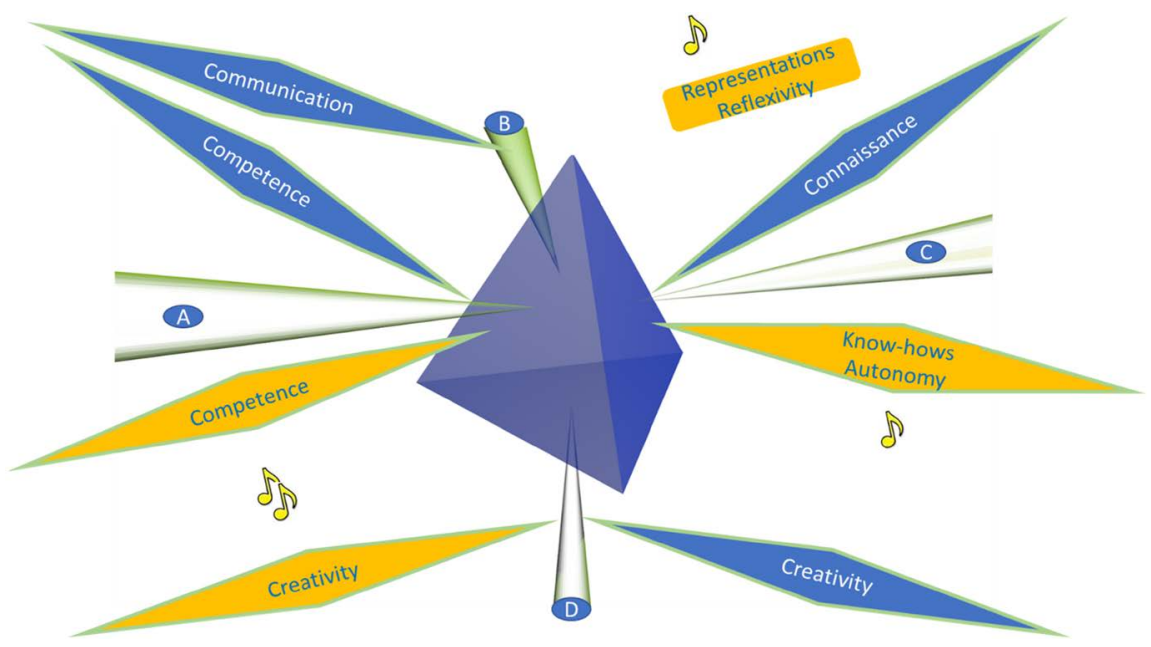

Figure 13. Jazz constructivism with alterity and altruism.

definitely a series of traits that innovation in the bigger data surrounding cannot miss.

Charles Calamel, (http://www.touteduc.fr/fr/archives), says: "Jazz is a model in that it leads the individual towards a self-direction in learning, a construction of oneself. Due to the conditions of play, the respect and transgression of codes and formats, jazz reverses the traditional pedagogic guidance system to set up a model of autonomy: it is not a question of receiving knowledge but rather of 'Go find it"'.

Fred Hersch's song title "Songs without Words" may further highlight the improvisation nature and emotional intelligence of creativity and innovation.

Emotional intelligence which may become more central to diversity innovative approach, to capture developmental potential, may not-or shall not be unless properly integrated - fit within or suit the trend of bigger data and ar- 
tificial intelligence interaction; although the later may be a source of improvisation as well. In a way we are getting closer to the AGI (artificial general Intelligence, Super-intelligence, Nick Bostrom (2017)), which tends to adapt to unknown situations like human makes use of emotion and intuition to choose and decide; a "jazzy" matter, virtually, terminologically. This is a Turing's reminiscence [10].

We can further summarize with a concluding list: Jazz is a model for learning innovatively being natural or, with some "artificiality", cooperatively conducted, to that extend it more particularly means: socializing, adopting, integrating, engaging, anticipating, predicting, improvising, inventing, creating, learning, selecting, otherness mirroring, regulating, representing, adapting , reflexivity practicing...

\section{Business as Usual}

\section{Let us be reminded}

A Science \& Business Equation for Collaborative Corporate Innovation or SME and start-ups is trilogical, Business Strategy/IP Strategy/R\&D Strategy in an all-in-one Business Model... AI supported? [54]

Most of the time IP strategy, R\&D strategy and Business strategy can no longer be separated and need to be linked. The three are to be integrated and harmonized in order to lean towards a more adapted and ideal business equation with an upfront business model analysis and implementation roadmap, i.e.:

1) Maintain Superior Competitive Position

\section{- Minimizing elapsed time from idea to market}

2) Ensure Business Flexibility

- Maintaining and expending the freedom to operate

3) Secure Business Profitability

- Minimizing legal/competition exposure

Indeed, it can get more and more complex. AI machine may compete with traditionally made innovation. Figure 14 oversimplifies such scenario, when indeed a human touch is brought into the design of a virtual AI claim interpretation.

Figure 14, is inspired from a virtual patent claim relating to the hospitality industry; "Apparatus and method to serve hot beverages, preferably coffee, without losing the human touch". No need to paraphrase the situation, either the AI made it hyper sophisticated or the co-inventor crossed the Rubicon, metaphorly

The harmonization of the 3 strategies, IP-R\&D-Business Roadmaps, is "best" done via the following algorithm, which indeed can be AI machined and further subject to machine learning and deep learning.

Here is a related harmonization best practice, "IF-THEN-ELSE" algorithm; preverbal:

1) Monitor the IP progress vs prior-art;

2) Refresh awareness of already in place secured technologies, via express inventories; 


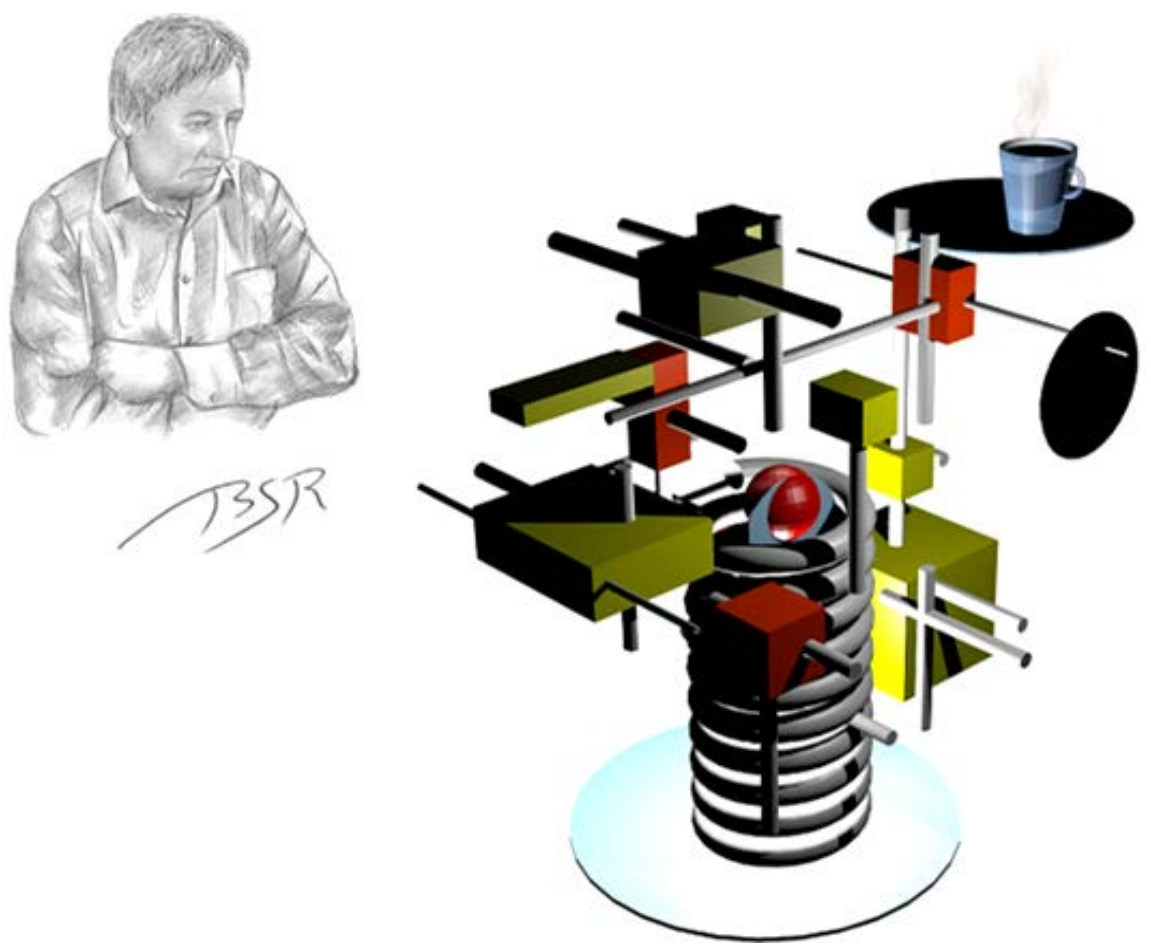

Figure 14. As social as a simple coffee cup.

3) Identify wish and must happen filings and acquisitions or divestitures;

4) Broadly recognize (manpower, resource, time) limitations of wide-ranging implications;

5) Regularly revisit lists of unexploited and unexplored technological traits;

6) Reformulate the ideal stage;

7) "Looping" back to most appropriate stage 1 - 5 .

Once internal mechanisms are in place and AI assistance well framed, the partnering is essential and conduct rules, below listed, could be applied, adapted and amplified given the latent AI supremacy.

Indeed, most of the time the necessity is to extend the open innovation composition and scope to apprehend "incidental" bias, for example.

1) Establishing and managing a reciprocal commitment process;

2) Adopting a process for the avoidance of the most common pitfalls;

3) Clarifying the prospect of future deals;

4) Favoring reciprocal value exchanges and value creation versus strictly value distribution schemes;

5) Monitoring constructively and putting in place early warning mechanisms;

6) Instituting efficient and easy to manage compensation mechanisms rules;

7) Avoiding hard bargaining tactics and excessive-lawyering;

8) Anticipating and eliminating "need" for hostage taking tactics and/or narrow-minded strategies to strictly insure return on investment.

Composition wise a few traditionally accepted roles will likely evolve facing AI context and careful impediment avoidance as reminded all along this study. 
One can easily identify some of them:

- The legendary gate-keeper focusing year after year on the maintenance and evolution of trade secrets and patent fortress or other patent styles therewith.

- The, coaching style, technology master, capable of creating year after year evolving generational technology packages with awareness of the routes to market and the business models.

- Freelance profiles, sometime perceived as "unmanageable" intrapreneurs (conversely entrepreneurs), take part to such controlling organization and are likely to bring non-core innovative solutions. They come generally from the problem solver side of the research organization; commonly originating from the sometime less appreciated problem spotter side of the business organization.

Figure 15 further illustrates.

All contributors identified above will team up to be the watchers of counterproductive bias; conditional to being familiar with AI-IP policy and strategy arena.

All members have a strong influence on the mechanisms of collective recognition in general and autonomisation, reflexivity, alterity, all already underlined. Humility is a team performance factor as well essential to a new open innovation dimension [55].

Heuristic, constructivism, reflexivity, alterity, autonomisation, reasoning under uncertainty, play it, do it, be it; all these terms set the tone to adapt open innovation to the $\mathrm{AI}$ environment at minimized risk.

To pictorially complement the various IP strategy models, we let the reader appreciate the self-explanatory Figure 16. The IP invisible edge [56] has never been so concrete under AI 4IR IP? I. R. Cornburn [57] reinforces the impact of AI on innovation therewith IP follows logically.

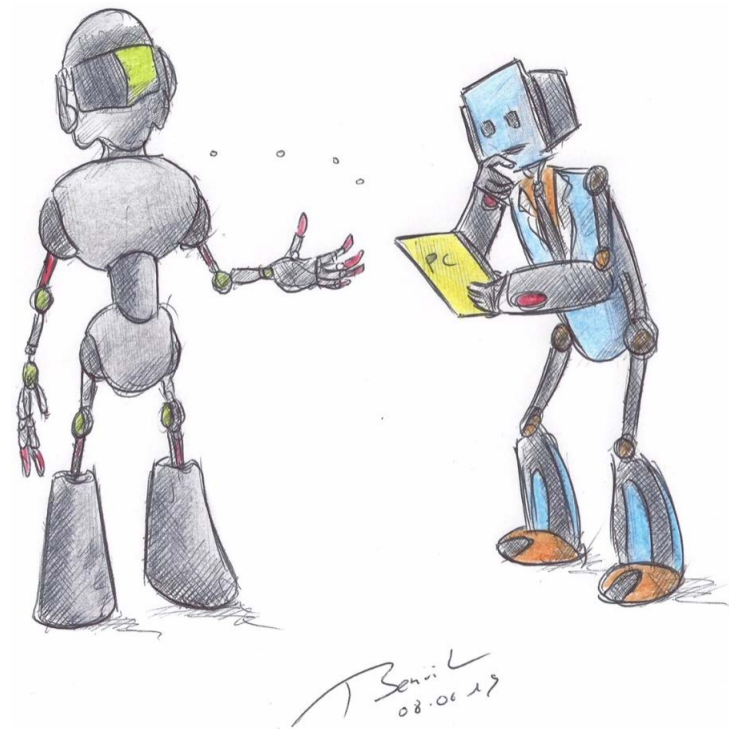

Figure 15. I left my brain home, may I pick on yours? 


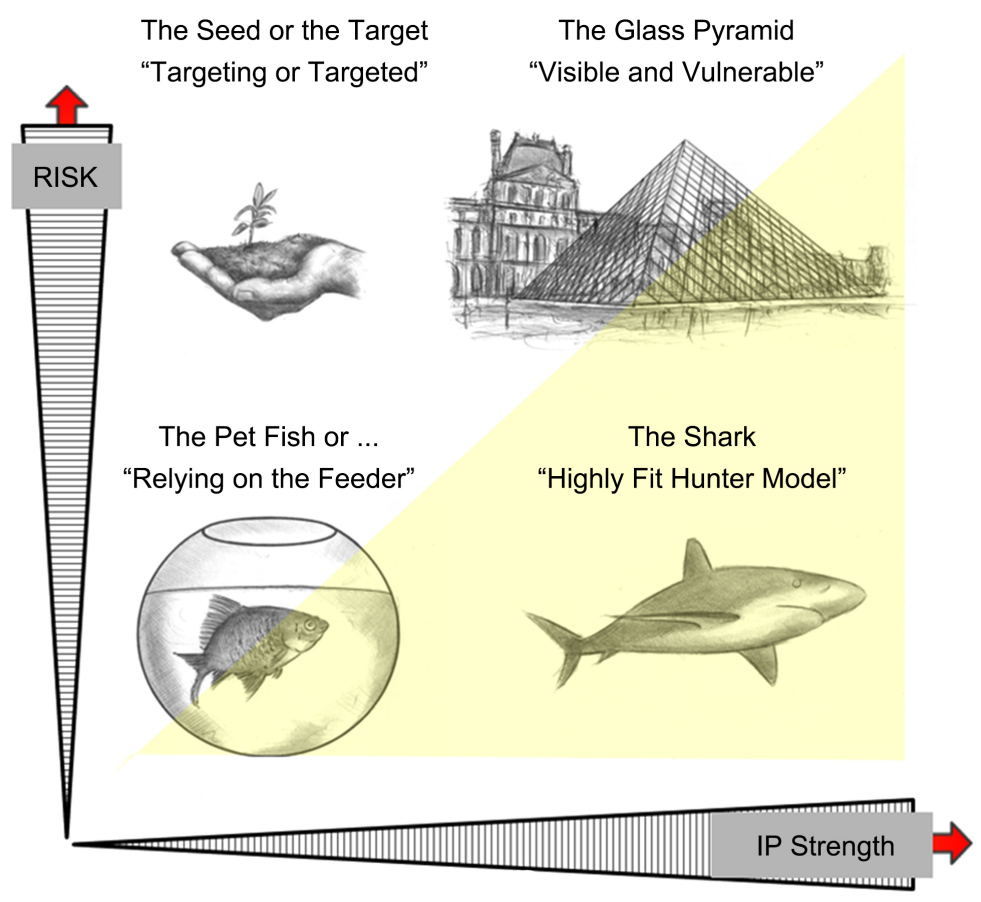

Figure 16. The innovation modes and their IP strength vs risk.

To conclude this business and innovation section overview; the picture rewards the climb once one discovers some already in place ethics protection scenarios subject to patents. Here are two examples, easily googled and self-described by their titles, which embedded algorithms would be rather easy to redesign as necessary for an implementation in an AI structure.

- Example 1 patent [58]

"Ethically coherent and scientifically logical method for allocating assets in portfolios of investments".

Abstract

The present invention concerns the technical aspects of applying ethics to the field of investment industry. It provides an ethically coherent and scientifically logical Method for allocating assets in portfolios of investments and a model Fund product that applies this Method to detract systemic tensions that generate frequent crisis of the financial markets in monetized economies. This is a novel mechanism to provide equality in access to both information and credit and thereby contributes to: a stable increase in financial return on investments; an optimal allocation of human resources through the creation of employment in both hard and soft currency countries, and an environmentally optimal depletion of natural resources through the development of democratic model of service economies in a continuous process. The implementation of the project is assisted by a computer program and a data base product, and monitored through an ethically coherent business organization method.

- Example 2 patent [59]

"System for assessing and improving social responsibility of a business". 


\section{Abstract}

The invention pertains to a system for assessing the level of social responsibility of a business and for monitoring improvements using the assessed level as a baseline. The system includes a self-assessment testing method which establishes a score or "grade" indicative of the level of social responsibility of the business which can be used for comparative purposes internally or externally. In terms of a business entity, the invention provides for a self-assessment process to objectively determine the level of social responsibility of the company in a manner subject to outside verification. The process isolates components of social responsibility. The results permit precise decision-making implementing change and reevaluation. The process results in a score or grade that is subject to verification or auditing by an outside agency in order that it will be a meaningful assessment outside of the confines of the company and in a broader community. It may be used for comparison to industry standards, universal standards, past performance, or the like. In broader terms, the invention provides a vehicle for a sponsoring agency or a collaboration of entities ("sponsor") to provide the business community with a means of verifiable self-assessment of the level of social responsibility of businesses. This permits the sponsor to adopt standards for the purpose of comparison of one business to another, to an industry group, to other industries, or to past performance.

\section{Further Reconciliation with EI}

\section{Within AI under automated supervision? Count what counts?}

It is not too difficult to reconcile the four selected essays and novel, referenced underneath, around a common human mandate; these seem to be popularly nominated as successes in the very recent publishing.

- "On the other side of the Machine. A scientist's journey to the land of algorithms" [6].

- "JAZZ: A Model for Learning. From music to self-construction, Insiders" [60].

- "Emotional robots. Health, surveillance, sexuality...: What about ethics in all of that?" [61].

- "Machines like me and people like you" [62].

These recent books are about, AI, algorithms, robots, machine supervised learning, deep autonomous learning vs education, ethic and ethics, human, bias, emotions, self-construction, constructivism, reflexivity, alterity, autonomisation, reasoning under uncertainty, ... although only one of them uses the extended keyword emotion* ( ${ }^{*}$ wildcard Boolean character), quite significantly, several hundred occurrences and much less for the three others. EI is apparently mentioned only twice in this most prolific one.

This should be most alerting and preoccupying, knowing that an artificial surrounding does not all.

To be self-comforted we examined a recent rather extensive 14 page's paper, 
by Taylor, S.A. et al., on predicting "tomorrow's" self-mood and wellbeing, a 7.2 $\mathrm{Mb}$ article, of 2017 [63]. Report "employing MTL (Multitask Learning) techniques to train personalized ML (Machine Learning [64] [65])". The word emotion*, with the wild character, is found 8 times including 5 in the references. EI is apparently unmentioned. Similarly, the word "feelings" does not seem to appear.

Is there a paradigm associated with: "what you feel is not what you get" via $\mathrm{AI}$ ? It better be visible/measurable. Our appreciation is strictly educative and illustrative, therefore "excessively pronounced", and would bear more substantiation first.

As underlined earlier on, in the brief introducing history of AI, a famous test, "of discernment of AI vs human?", was introduced by Turing in his 1950 paper, "Computing Machinery and Intelligence", while working at the University of Manchester (Turing, 1950; p. 460). On line at https://en.wikipedia.org/wiki/Turing_test [10].

"Should the test, be daringly, further adapted to EI discernment to revitalize it and limit controversial interpretative bias?"

Emotional intelligence as a creative nugget, or sense of self control, has a play in the $4 \mathrm{IR}$ ? Let's progress our propos on a better understanding of EI facets. Typically, what EI-is, is not, maybe, should be or become, in the AI spiraling tornado?

Beneath, a condensed essay, from M. Lapray, summarizes some of the above and raises "a fundamental invention differentiation issue".

\section{The Inventor and AI, EI: A Short Essay}

Artificial intelligence (AI) is already present in some forms around us and is used in number of domains such as healthcare, banking, retail or manufacturing and it thus naturally becomes also present, to some degree, in the technical innovation process. This development has pushed policymakers to re-consider some of the Intellectual Property (IP) concepts, one of them being the question whether AI can be an inventor. This essay will further briefly probe who is an inventor and how he/she/it and by extension their inventions could be characterized.

In 2020, the European Patent Office (EPO) has rejected two patent applications that designated an artificial intelligence named DABUS (AI DABUS) as the inventor 1) Food container-EP18275163.6/EP3564144 and 2) Devices and methods for attracting enhanced attention-EP18275174.3/EP3563896; EPO press release and links to the decisions: [36]; appeals have been filed). Although, applications at issue describe two AI-generated inventions, the EPO has considered that the inventor designated in a European patent must be a natural person. Patent applications designating DABUS as the inventor were also filed in UK and US. Similar legal interpretations were applied by the UK's Intellectual Property Office (UKIPO) and US Patent and Trademark Office (USPTO) that both ruled 
out that DABUS cannot be listed as an inventor and that the patent applications fail to meet formal requirements (GB1816909.4 and GB1818161.0 [66]) and (US16/524350 [67]).

In the cited EPO decisions we read that the patent applicant and owner of the AI DABUS, Stephen Thaler, explained that the machine "identified the novelty of its own idea before a natural person did", similarly on the The Artificial Inventor Project website it is described that the inventions were created autonomously by AI DABUS [68]. Nevertheless, the above EPO's, USPTO's and UKPTO's decisions seem reasonable and straightforward given the current legal provisions that would not allow AI to be an inventor on a patent application. It's important to note that these decisions focus solely on procedural requirement and do not answer the question whether AI-generated inventions are patentable. This remains to be established in a separate examination. It is likely that these inventions are, in general, patentable, however even this fact could not lead us to answer whether AI-generated inventions are identical/similar to inventions originated from a human idea, conception and need. The true potential value of AIvs. human-generated innovative solutions remains to be assessed with increased number of such cases.

It's trivial to state that the AI- and human-generated inventions have fundamentally different origin. On one end we deal with a technology that is designed to process complex problems and enormous amount of data and that merely simulate human intelligence without its emotional component. On the other end we have a human brain that is incapable of processing large data sets and human cognition tied with emotions.

It is now evident that emotions and cognitive processes reciprocally impact each other and are inseparable "forces". Emotions, independently of how we define them, influence our perception of the environment, attention, memory and decision-making, and thus influence innovation process executed by a human (e.g. review [69]).

It is obvious that emotions (or emotional intelligence) are crucial components of human intelligence, and that the part of emotional intelligence (EI) is essentially missing in AI. For the purpose of this essay, EI is understood as defined by Peter Salovey and John Mayer, as "the ability to monitor one's own and other people's emotions, to discriminate between different emotions and label them appropriately, and to use emotional information to guide thinking and behavior" [70]. Importance of emotional processing aspect can be intuitively understood based on a difference between language and communication, in the context of AI-powered chatrobots (chatbot) and language translators. Clearly, AI can learn to recognize and translate by far many more languages than any human (language per se), however at the moment it cannot integrate into this translation subtleties of culture associated to a group speaking a particular language, abstract concepts, or emotional state of a human (communication) [61]. Recognizing importance of EI inevitably leads to an attempt to artificially recognize, 
process and simulate human emotions (known as affective computing) [71]. One can only imagine unlimited applications of affective computing in education, healthcare, social monitoring and the like. At the moment, for example creating wellbeing predictors for people with different personalities and lifestyle could better forecast personal outcomes in their physical and mental wellbeing [63].

Even if, AI could be able to perceive and simulate to express affect (category IV of affective computing; Picard, supra) and would learn how to interact with humans, it does not mean it will have any trait of EI that would influence its processing leading to innovative ideas. This leaves us with plenty of open-ended questions that remain to be answered with time. Can AI conceive a truly innovative solution that is patentable? If yes, does AI- and human-made inventions are same or clearly different? If different, then in what way? Is it likely that human-made inventions will always be "more creative" than AI-made inventions? Can inspection of the technical invention give a clue on who was the inventor?

Unquestionably, the development of AI has already started the discussions on at least the subject of inventor rights and patentability of AI-generated solutions. It seems that this only opens further discussions on quality/characteristics of technical innovation derived from human inventor that implicitly hold some form of EI vs. those derived from AI that fundamentally lack EI component.

Figure 17 further illustrates.

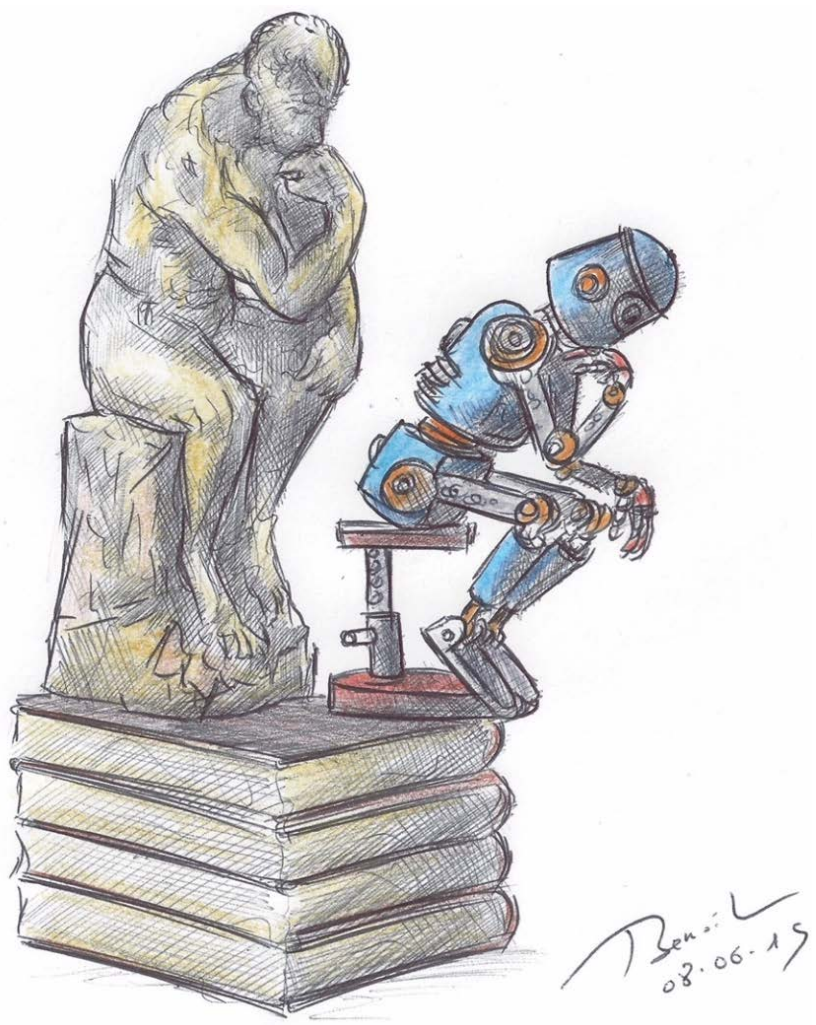

Figure 17. Deep thinking in a deep learning environment. 


\section{Sport as an Illustrative Model}

\section{$E I$ and motivation in a normalized and formatted environment with/ without $A I$, to what extend?}

AI, EI, are common in life events including sports which IP dimension is sizable from brands \& trademarks, knowhow \& trade secrets, copyrights \& related rights, as well as designs \& patents. The use of the patent classification code A63, related to applications for patents covering "sports, game, amusements", is growing sharply and steadily for last 2 decades. Indeed, IP assists in protecting the business value of rugby and its rights. "All Blacks brand" soon worth $\$ 1 / 2$ Billion, seen on press releases. Toulouse rugby, "game in motion" is an ever-ongoing evolving legacy.

AI is taking part in form of method claims such as "System and Method for creating a team sport community" which incidentally includes players statistics, among other criteria, comprises 71 claims and 50 plus pages of specifications with 36 figures.

As seen before the innovation and emotional intelligence (EI) do not diverge on several aspects of the works of mind which is part of moral rights as seen previously. Ethics isn't far away.

Multiple "facettes" of sports, in general, depends on EI dynamics, the question of interest is to review the status of the trilogy AI-IP-EI in sports involving teams. A few paradigms may not survive or new ones may appear with the advent of the $4 \mathrm{IR}$, and $\mathrm{AI}$ inevitable waves?

Unavoidably, resulting situations are such:

Among the trainers/teachers using some form of artificial intelligence or assistance, the following happens:

- coaches/teachers overwhelmed by the weight of the data,

- disciplined, conditioned coaches/teachers strictly respecting or favoring the weight of the data,

- well informed wiser coaches/teachers selecting and relying on the data.

Ensuing are oversights, such as development, interpersonal and individual skills, lack or excess of precision versus recall, of game rules.

Rugby is a good example of team approach whereby players are merely physically "face-to-face" exposed dually to EI and open or closed innovation in the course of actions for the sake of providing entertainment and sustainable profit at professional level.

Questions are practical; either invest huge amount of time on data analysis and/or let the AI machine dictates its global, averaged and standardized agenda or do otherwise.

EI, IP (economics and moral rights) and resultant natural and educated motivation may have alternative say in this dilemma.

Bias characteristics that we have detailed before, 50 listed, are completely applicable to this situation. 
Let's the rugby experts talk first and then we will try to unveil a simple way mediating this duality in a human centric manner.

The genre, in rugby, being the operationalization of a regulation, set of rules, or its interpretation by an adaptation of skills on the strategic and tactical plans of the teams (Bouthier, 2000 [72]). It is a common part of the activity updated and shared by its practitioners; a form of interaction described by Clot \& Faïta (2000, p. 12 [73]) as "the bridge between formal and prescribed operationalization of material equipment, and, the ways of acting and thinking by the involved milieu". Bouthier et al. (2011 [74]) observed the evolution of the genre in rugby and proceeded to a comparative analysis of the rhythm of play and the types of phases mobilized during different events (world cups 1999 and 2007).

As for the style, i.e. expression or transformation of the genre- "way of"-by a team, it is, in collective team sport, the use of forms of play and their alternations in order to create a singular sequence. The style of play, resulting from particular initiatives but also coordinated, involving and implementing, original and privileged, individual and collective techniques (Bouthier et al., 2011 [74]), is characterized by a transient state in comparison to the genre: it can vary from match to match, from competition or season to season.

Sizable number of field practice observations, leads us to question the distance between the style and the genre of play. In a context where expected performance analysis procedures, are becoming more and more standardized.

Rules changes aim at modifying the genre to orient the teams' playing style. A smoothing (or reproduction/harmonization) of styles, a reduction of the genre/play style gap encouraged by the concentration and the influx of data, may exclude a certain number of elements inherent to the complexity of this collective team fighting game. A clear imbalance, bias, lies in the way of "feeding" the machine. Therefore, adopting a technological path at more elevated altitude view one may embark to undetermined destination, without pilot?

The term "context" is associated with the variables in the following non-exhaustive list with which the protagonists, in their environment (mainly the action), interact:

- the form and level of opposition and composition encountered,

- the moment of the action (in the season, the match, the sequence of play...),

- the location of the action (place of the game, place of the movement of play, set-up...),

- the scenario of the match (score, injured players, sanctioned players...),

- the emotional load affecting the player, his partners and his opponents...

Then a form of situational intelligence will prevail where players will draw on the resources developed or unexplored at this stage to provide the solution to the problem encountered.

Deleplace's work (1979, 1983 [75] [76]) on the concept of tactical intelligence, by distinguishing different angles (man against man, reduced and total team) in situations presenting changing opposition relationships, has helped to explore 
the components of complexity of the systemic relationship between players and their milieu.

To what extent does the technological tool and the data processed, without the EI components, support the coach's flair and paradigm? Seems to be the right question at the right time isn't it?

On a more heuristic tone, based on know-how and practical experienced, the famous French Flair is not an improvised cacophony but organization where the common frame of reference heartily shared and praised by René Deleplace and his disciples, (Bouthier, 1988, 2000 [72] [77]; Bouthier \& al., 1994 [78]; Brochard, Jeandroz \& Villepreux, 2007 [79]; Deleplace, 1966, 1979, 1983 [75] [76], [80]; Dury, 2018 [81]; Jeandroz, 2018 [82]) allows the initiative of the player within a collective teams dimension. A slanted language would reduce this to an individual initiative?

The rather heteroclite, forms and levels of composition governing the coordination of the initiatives of a rugby team, attract the attention on the mechanisms of intra-group influence of the components of sports action described by Bouthier (1989, 1993, 2014, 2016 [83] [84] [85] [86]), within the game situation, according to different opposition or composition proportions.

Incidentally, and complementary to above, Campo et al. (2019 [87]) focus, in line with current practices, on the interindividual differences by considering the place of the match ("at home" or not) as some contextual variable.

After the experts' enlightenment, it is opportune to come back to a more profane elementary question related to collective versus individual concordance of emotional skills, on time and/or differed.

Based on reflexivity on one side and alterity on the other, concept already developed in this study around the jazz special model of constructivism, here are ten individual and team emotional skills from R. Shankland. C. André, (2020 p 178 [88]) that may provide a solution once in place, monitored, nurtured and constantly subject to motivational motion.

1) Identifying one's own emotions;

2) Identifying other people's emotions;

3) Understanding one's own emotions;

4) Understanding other people's emotions;

5) Expressing one's own emotions;

6) Listening to other people's emotions;

7) Regulating one's own emotions;

8) Helping the other persons regulate their emotions;

9) Use your own emotions to make decisions;

10) Using the emotions of others.

The schematic of Figure 18 (Rebouillat A. \& Curty M., 2019 [89]) goes along and self explains the dynamic nature of motivational education, possibly part of the dream team magicality. It is not a static pattern, keeping forever the player/pupil at his assigned position and role. Motion is motivational in essence 
and developmental.

Figure 18 is a non-exhaustive representation of the forms of differentiation of inter-individual relationships according to individual interest and the goals of achievement pursued by the students.

The constitution of groups and differentiation, as depicted in Figure 18 through the interactions generated are decisive educational actions. Going from one plan to another, by associating more or less disparate emotional and motivational profiles, the practitioner operates by generating or maintaining a form of collective energy in the direction of the commitment of each actor and his need for development. A permutation of toothed cogs oiled by unifying emotions, whose contagion mechanisms coming from its leaders can be observed from the same angle as the motives for action or the virtues (Owens B.P., David R. Hekman, 2016 [55]).

An emotional contagion (Campo \& Djait, 2016 [90]) where a player's emotional state could be felt and adopted by his teammates (Parkinson \& Simon, 2009 [91]).

This is especially remarkable when a shortfall team over turns the fate of the game. Examples relate to rugby specialists and fan clubs; e.g. Racing rugby Parisian team which made it to the final ultimate stage that way in 2016 in Barcelona, way from its home. This is an academic model case as well in terms of EI. Not to be forgotten, as mentioned in the course of this paper, similarly, a derailment of opponent plan can be a tactical bias favored in sport, which can have EI trait.

Definitely AI can't do it all, EI needs to be reconciled once more. Game tactic and strategic innovation enjoys room for further development with data management intelligence.

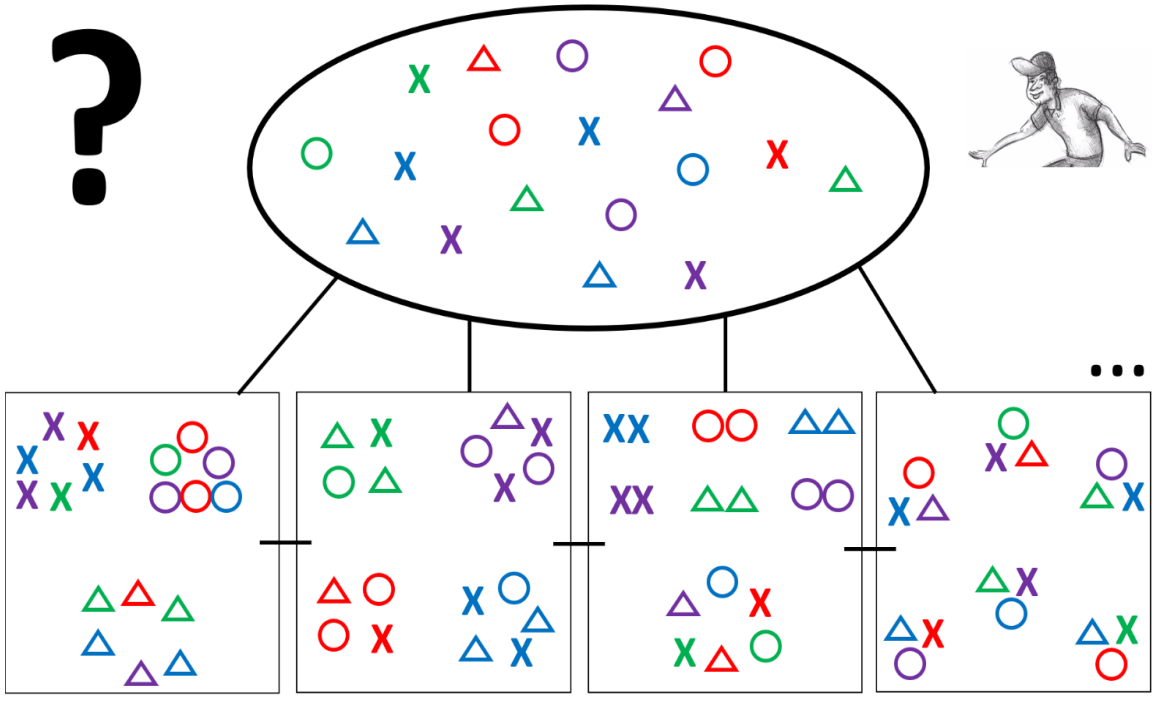

Figure 18. Dynamics of mixed \& enriched team compositions with the following legend: $\mathrm{X}$ : positive affect and willingness to reengage; $\mathrm{O}$ : stored utility value; $\Delta$ : stored attainment value; purple: mastery-approach goal; green: mastery-avoidance goal; red: performance approach goal; blue: performance-avoidance goal. 
This case study on sport and education further underlines the AI-IP-EI TRILOGY intrinsic and explicit coherence.

\section{Conclusions}

"If the three fundamental areas of language, vision and reasoning are widely explored today, emotional intelligence is still an emerging area." (The emotional robots, Laurence Devillers [61], p. 245).

This could not remain unattended and urged us to move on with our agenda to let the matter being further discovered.

"The Innovation Wall" (Figure 1) is going through its fourth revolutionary industrial (4IR) building stage via Bigger Data and Artificial Intelligence (AI) vectors; such as "Another Chip in the Wall".

The implicit meaning of the famous lyrics' "Another Brick In the Wall" by Pink Floyd, 1979, endorses various emotions left to interpretation (2014 [1]). Nonetheless a flavor of mechanical harmonization of the time tends to agree with some resentment brought-in similarly today by AI and its ability to "digitize" emotional intelligence (EI), sometime regardless.

Some consensual streams seem to have established themselves at a rather steady state, active as a background flux; around concerns, questions, fears, issues, controversial data, ethics, security, hacking, privacy, consent... however an immense opportunity is recognized.

Disclosed funding in $\mathbf{2 0 1 8}$ provides further insight into AI activity... representing about US $\$ 46$ billion in total p. 35 [9].

In 2019 from 52 EU Experts [11]_"EU HLEG’s 'Ethics Guidelines for Trustworthy AI' is made Public" [32].

Simultaneously, EPO rejects proposal of AI Machine inventor name, in the autonomous DABUS application inventions.

Bias, intrinsically anchored in AI founding algorithms and labeling practice, as well as relevant IP (Intellectual Property) data protection, their roots and evaluation, are subject to this highlighting and alerting done in an open and constructive manner. In this context "The Technology Trap" by Carl Benedict Frey, 2019, [2] coincidentally resonates stridently at the time of writing this article. Current viral pandemic, likely to be revealing a broadly anchored technology gap, cannot rest unmentioned either.

A rather comprehensive list of bias descriptors is worth repeated examinations. Now being more largely adopted, thanks to contributors [3] [6] [27] [61] time for active and autonomous supervision is pressing.

These considerations "fall into four broad main categories; bias, transparency, accountability and privacy".

Those are good keywords, fitting well with our current propos on AI-IP-EI Trilogy. This statement [9], pp. 121-122, is added to some crucial aspects of reputation and trust with brand's IP endangerment and puts, back in place, the economy part in case of underestimated risks. "Artificial Intelligence Collides 
with Patent Law, 2018" [48] seems to be acknowledged as well. Indeed AI-IP-EI Trilogy may affect a number of legal schemas.

Among other moral rights, ethics positions and initiatives from most visible, at least 7 institutions in the domain, the UNESCO's [44], regarding their absolute position of no use of AI without human control in war conflict situations, are essential either.

AI is sometime compared to new electrifying and running supply water in any household, except that those utilities are not, apart from expected catastrophic climate happenings, determined by bias possibly affecting their "raison d'être" in their fundamental basic usage.

C. B. Frey the author of the extended essay [2], p. 11 cites W. Churchill who quipped that "The longer you can look back the farther you can look forward". With precaution and rational Toni Morrison in her address and reflection in "The Source of Self-Regard", 2019, [3] tends to keep distance from "notorious" references that may reduce both the author's and the reader's fresh imaginations. This is an authentic respect incentive for induced privacy.

Additive to the preceding quotes one may agree that the invention of the telescope raised far less anxiety than some other discovery technologies. Indeed, it brings closer faraway background details to help "visualize" and comfort the horizon.

Could a human centric, AI-adapted-IP policy, internationally embraced, take part to some level of arbitrage, normative and enduring reliability in the field of interest? This seems to be "en route". Shall the EI (Emotional Intelligence) factor be supervised? Likely so; then is traditional open innovation to a more comprehensive, more inclusive dimension reminding best business practice and their "beyond"? Definitely, and will remain an opportunity, all along the 4IR quantum game changer to come.

Business wise, "as usual"? Anew open innovation dimension unveils the necessity that all contributors identified therewith will team up to be the watchers of counterproductive bias; provisional to being familiar with AI-IP policy and strategy arena.

All members have a strong influence on the mechanisms of collective recognition in general and autonomisation, reflexivity, alterity, all already underlined at several instances. Humility is a team performance factor as well, essential to a new open innovation dimension [55].

Heuristic, constructivism, reflexivity, alterity, autonomisation, reasoning under uncertainty, play it, do it, be it; all these terms set the tone to adapt open innovation to the $\mathrm{AI}$ environment at minimized risk.

This aspect is here treated as a penta-polar simplifying proposal, of the main author [47], towards improving the AI to IP course; such as the WIPO draft.

Acronymized @LEAST@, it covers the ensuing specificities:

- L., Legal;

- E., Ethical, Equitable; 
- A., Advanced, Accountable, Accessible;

- S., Safe, Secured;

- T., Tolerable.

Furthermore, the key, 2019, EU requirements for achieving trustworthy AI [32]:

- human agency and oversight;

- robustness and safety;

- privacy and data governance;

- transparency;

- diversity, non-discrimination and fairness;

- societal and environmental well-being;

- accountability.

Neither seeking an in-depth expert analysis, nor a grand public over-simplified bavardage, of the trilogy, AI-IP-EI, four authors here propose an illustrated view of educational, visionary, demonstrative value to the subject matter.

They are aged about 30-40-50-60, being IP\& Innovation strategist, future IP lawyer, children teacher and professional academy sport coach, illustrator and bio-advanced materials engineering "Fellow".

With experience of large and smaller organizations, being involved innovators, inventors and private artists as well, they are sharing their "non-jargonized down-to-earth", forward looking views through a structured analysis of the trilogy using realistic examples and data from rather diverse specialized independent sources.

New invention and inventorship been "reconceptualized" at least from an "insighter or insider" viewpoint (M. Lapray's inserted short essay), sport team approach more broadly revisited from its academy level to its commercial asset impact, via educational virtues and values by A. Rebouillat. Music improvising group constructivism enters the scene as well with its exemplary components of reflexivity and alterity valued for open innovation.

Based on reflexivity on one side and alterity on the other, concept already developed in this study around the jazz special model of constructivism, are proposed the ten individual and team emotional skills from R. Shankland. C. André, (2020 p. 178 [88]) that may provide a complementary sport team dynamic solution once in place, monitored, nurtured and constantly subject to motivational motion.

The schematic of Figure 18 (A. Rebouillat \& Curty, 2019 [89]) goes along and self explains the dynamic nature of motivational education, possibly part of the dream team magicality. It is not a static pattern, keeping forever the player/pupil at his assigned position and role. Motion is motivational in essence and developmental.

On a closing, conclusive business tone, it appears from our touch of IP sampling that the current $\mathrm{AI}$ open innovation profile encountered would rather fit a semi-open innovation pattern as we have illustrated before in the business sec- 
tion.

"Emotional intelligence, EI, is still an emerging area within AI" and beyond. A new open innovation scheme is taking place.

This prompted our intention to further contribute to this matter. Indeed, EI is, the tree gently challenging the wind; of AI and IP impetuousness. AI IP is ready to seize EI autonomously translated features...?

\section{Acknowledgements}

The authors thank:

- Fernand Pla: Science Emeritus, sums the aura of a Sommité.

- Benoit Steffenino: for design, the illustrations and the artistic codesign with main author. An essential interpretational inspiration in the field.

- Miroslawa Lapray: for her exceptional ability to consolidate massive complex matters and make them accessible to most with refined analysis. Author of section "The Inventor and EI: A Short Essay".

- Antoine Rebouillat: for his freshness and ability to make rugby academy an art and a science pertinent to education innovation thereafter; which generated significant open and innovative exchanges. Author of section "Sport as an Illustrative Model".

- Antoine Piccirilli: renown entrepreneurial scientist; for multiple discussions of high relevance.

- Imre Horvath: "most demanded" business strategist; his rationality and implementation talents are key drivers to meet such milestone. A "jealously sought-after, inspirational effective Master".

- Nicolas Cudré-Mauroux: "door opener with phenomenal drive", determinant in bringing such matters "up to stream" in large institutions, beyond their traditional inertia.

- France Rochette: gate keeper in business relevance analysis with a distinguished and highly balanced, technology/busines mindset. Her people-approach magical fluency, makes the difference.

- Corneille Schmitz: for enlightening conversations on Science and Emotional Intelligence, and Privacy Governance.

\section{More about the Authors}

Serge Rebouillat [Phonetically: Rebooya], Dr Ing., Docteur ès Sciences, Certified Prof., Ind. Energetic, Chem/Bio Eng., Rheology, IP: Mediation/Innovation \& Strategy/Management/Valuation.

Benoit Steffenino, Fellow, Certified Ing., Scientist.

Mirosława Lapray, Trainee Patent Attorney (EQE, part qualified), DPhil Pharmacology (Oxford).

Antoine Rebouillat, Certified HEP Teacher (M.S.), Certified Rugby Academy Coach. 


\section{Disclaimer}

This article is primarily for educational purposes. Selected cases are strictly illustrative. Neither the authors nor the illustrators assume any liability for any errors or oversights, for how this article or its contents are utilized or interpreted or for any consequences resulting directly or indirectly from the usage of it.

This information is for general knowledge. For critical applications, requirements should be checked with the suppliers. For additional guidance, legal or any other, seek advice from the appropriate qualified professionals; this study can by no means substitute for legal, technical and managerial expert advice.

The opinions expressed by the writers in this article do not necessarily represent the viewpoints of the company the authors are employed by.

\section{Conflicts of Interest}

The authors declare no conflicts of interest regarding the publication of this paper.

\section{References}

[1] The Real Meaning of "Another Brick in the Wall" by Pink Floyd. http://composingwritingv2.weebly.com/project-text/the-real-meaning-of-another-b rick-in-the-wall-by-pink-floyd

[2] Frey, C.B. (2019) The Technology Trap. Princeton University Press, Princeton.

[3] Morrison, T. (2019) La Source de l'Amour Propre. Christian Bourgois Éditeur, Paris.

[4] Pierce, T.H. and Horne, B.A. (1985) Artificial Intelligence Applications in Chemistry. In: ACS Symposium Series 306, American Chemical Society, Washington DC. https://doi.org/10.1021/bk-1986-0306

[5] Popovic, D. (1994) Methods and Tools for Applied Artificial Intelligence. CRC Press, Boca Raton.

[6] Jean, A. (2019) De l'autre côté de la Machine. Voyage d'une scientifique au pays des algorithmes [On the Other Side of the Machine. A Scientist's journey To the Land of Algorithms]. Éditions de l'Observatoire/Humensis, Paris.

[7] Lupu, M. (2018) Artificial Intelligence and Intellectual Property. World Patent Information, 53, A1-A3. https://doi.org/10.1016/j.wpi.2018.06.001

[8] https://www.antidote.info/fr/antidote-10/documentation/guide-utilisation/les-dicti onnaires/dictionnaire-des-champs-lexicaux

[9] WIPO (2019) WIPO Technology Trends 2019: Artificial Intelligence. World Intellectual Property Organization, Geneva. (as per WIPO suggested citation)

[10] https://en.m.wikipedia.org/wiki/Alan_Turing https://en.wikipedia.org/wiki/Turing_test

[11] https://ec.europa.eu/digital-single-market/en/high-level-expert-group-artificial-inte ligence

[12] https://www.fiveipoffices.org/contact

[13] https://ec.europa.eu/newsroom/dae/document.cfm?doc_id=56341

[14] https://e-courses.epo.org/pluginfile.php/57375/mod_page/content/21/AI\%20and\%2 
0inventorship\%20patentability.pdf

[15] https://en.unesco.org/artificial-intelligence

[16] https://www.wipo.int/reference/en/wipopearl/news/2019/news_0004.html

[17] Rebouillat, S. and Noirhomme, B. (2018) Open-Innovation in the Electrical and Electronic Industries: Engineered Bio-Fluid Compositions Are Paving the Way, and Testing Therewith. Journal of Biomaterials and Nanobiotechnology, 9, 189-209. https://doi.org/10.4236/jbnb.2018.92011

[18] The EPO PATENT INDEX 2019 Infographic. https://www.epo.org/about-us/annual-reports-statistics/statistics/2019.html

[19] EPO Copyright Terms and Conditions. https://www.epo.org/footer/terms.html

[20] WIPO IP Facts and Figures 2019. https://www.wipo.int/edocs/pubdocs/en/wipo_pub_943_2019.pdf

[21] Fujii, H. and Managi, S. (2017) Trends and Priority Shifts in Artificial Intelligence Technology Invention: A Global Patent Analysis. Research Institute of Economy, Trade and Industry, 17-E-066.

https://voxeu.org/article/trends-artificial-intelligence-technology-invention

[22] Lupu, M., Mayer, K., Kando, N. and Trippe, A.J., Eds. (2017) Current Challenges in Patent Information Retrieval. In: The Information Retrieval Series, Vol. 37, 2nd Edition, Springer, Berlin. https://doi.org/10.1007/978-3-662-53817-3

[23] Rebouillat, S., Lapray, M. and Lapray, D. (2013-2014) IJIAS. http://www.ijias.issr-journals.org/authid.php?id=509

[24] Rebouillat, S., Pla, F. and Ortega, S. (2013-2019) JBNB. https://www.scirp.org/journal/Articles.aspx?searchCode=Rebouillat\&searchField=A ll\&page $=1 \&$ SKID $=59213665$

[25] O'Connor, P.J., Hill, A., Kaya, M. and Martin, B. (2019) The Measurement of Emotional Intelligence: A Critical Review of the Literature and Recommendations for Researchers and Practitioners. Frontiers in Psychology, 10, 1116. https://doi.org/10.3389/fpsyg.2019.01116

[26] https://www.wipo.int/export/sites/www/standards/en/pdf/03-15-01.pdf

[27] Tali, S. (2011) The Optimism Bias: A Tour of the Irrationally Positive Brain, Vintage. Vintage Books, New York.

[28] Rebouillat, S. and Rushton, A., Eds. (1985) Mathematical Models and Design Methods in Solid-Liquid Separation. Martinus Nijhoff Publishers, Dordrecht.

[29] https://www-edlab.cs.umass.edu/cs240/lectures/lecture1.pdf

[30] Kahneman, D. and Tversky, A. (1974) Judgment under Uncertainty: Heuristics and Biases. Science, 185, 1124-1131. https://doi.org/10.1126/science.185.4157.1124

[31] Rebouillat, S. and Pla, F. (2019) A Review: On Smart Materials Based on Some Polysaccharides; within the Contextual Bigger Data, Insiders, "Improvisation" and Said Artificial Intelligence Trends. Journal of Biomaterials and Nanobiotechnology, 10, 41-77. https://doi.org/10.4236/jbnb.2019.102004

[32] https://ec.europa.eu/newsroom/dae/document.cfm?doc_id=60419

[33] https://www.europarl.europa.eu/RegData/etudes/BRIE/2019/640163/EPRS_BRI(201 9)640163_EN.pdf

[34] https://www.fiveipoffices.org/wcm/connect/fiveipoffices/5e2c753c-54ff-4c38-861c-9 c7b896b2d44/IP5+roundtable+on+AI_report_22052019.pdf?MOD=AJPERES\&CVI $\mathrm{D}=$ 
[35] https://www.fiveipoffices.org/wcm/connect/fiveipoffices/69f238e9-e2be-4fb1-83ee-c b5796d2679e/HI-AIPLA-AI+Presentation.pdf?MOD=AJPERES\&CVI

[36] https://www.epo.org/news-events/news/2020/20200128.html

[37] https://www.wipo.int/edocs/pubdocs/en/wipo_pub_909_2016.pdf

[38] Cath, C., et al. (2018) Governing Artificial Intelligence: Ethical, Legal and Technical Challenges and Opportunities. Philosophical Transactions of the Royal Society A: Mathematical, Physical and Engineering Sciences, 376, Article ID: 20180080. https://doi.org/10.1098/rsta.2018.0080

[39] Council of Europe (2017) Algorithms and Human Rights. Study on the Human Rights Dimensions of Automated Data Processing Techniques and Possible Regulatory Implications. Committee of Experts on Internet Intermediaries (MSI-NET). Council of Europe, Strasbourg.

[40] Zech, H. (2016) A Legal Framework for a Data Economy in the European Digital Single Market: Rights to Use Data. Journal of Intellectual Property Law \& Practice, 11, 460-470. https://doi.org/10.1093/jiplp/jpw049

[41] Kerber, W. (2016) Governance of Data: Exclusive Property vs. Access. International Review of Intellectual Property and Competition Law, 47, 759-762. https://doi.org/10.1007/s40319-016-0517-2

[42] Lorica, B. (2018) Data Collection and Data Markets in the Age of Privacy and Machine Learning. O’Reilly on Our Radar.

https://www.oreilly.com/content/data-collection-and-data-markets-in-the-age-of-p rivacy-and-machine-learning/

[43] Juste, R., et al. (2017) Four Ethical Priorities for Neurotechnologies and AI. Nature, 551, 159-163.

[44] https://unesdoc.unesco.org/ark:/48223/pf0000367422?posInSet=2\&queryId=325cbc a9-7ad3-4265-8118-88c3dc451766

[45] https://www.wipo.int/pressroom/en/articles/2019/article_0017.html

[46] https://www.wipo.int/about-ip/en/artificial_intelligence/submissions-search.jsp

[47] https://www.wipo.int/export/sites/www/about-ip/en/artificial_intelligence/call_for_ comments/pdf/ind_rebouillat.pdf

[48] World Economic Forum (2018) Artificial Intelligence Collides with Patent Law. WEF Centre for the Fourth Industrial Revolution, Cologny/Geneva.

[49] Rebouillat, S. (1998) Foresee Concept and Young Chemists Industrial Training. The “4C" Skill Balance and the "Intrapreneur". L'Actualité Chimique, 214, 23-24. https://www.lactualitechimique.org/numero/425

[50] Lapray, D. and Rebouillat, S. (2014) "Bigger Data” Visualization to Visual Analytics: A Path to Innovation. "Happening, Definitely! Misleading, Possibly?" A Review of Some Examples Applicable to IP Discovery. International Journal of Innovation and Applied Studies, 7, 1251-1273. http://www.ijias.issr-journals.org/

[51] Lapray, M. and Rebouillat, S. (2014) Innovation Review: Closed, Open, Collaborative, Disruptive, Inclusive, Nested... and Soon Reverse. How about the Metrics: Dream and Reality. International Journal of Innovation and Applied Studies, 9 , 1-28. http://www.ijias.issr-journals.org/

[52] Rebouillat, S., Lyons, M.E.G., Doyle, B.M.P. and Richard, L. (2011) Paving the Way to the Integration of Smart Nanostructures: Part II: Nanostructured Microdispersed Hydrated Metal Oxides for Electrochemical Energy Conversion and Storage Applications. International Journal of Electrochemical Science, 6, 5830-5917. 
[53] Calamel, C. (2010) Le jazz comme science d'éducation: Vers un modèle explicatif du jazz à partir de la formation des savoirs du jazzman. $\mathrm{PhD}$ Thesis, University of Paris 10, Paris. https://en.calameo.com/books/000162058c7aea20f47f4

[54] Rebouillat, S. (2013) A Science and Business Equation for Collaborative Corporate Innovation. Business Strategy, IP Strategy, R\&D Strategy: An All-in-One Business Model. A Review with a Bio-Technology and Green Chemistry Focus. International Journal of Innovation and Applied Studies, 4, 1-19.

http://www.ijias.issr-journals.org/N

[55] Owens B.P., David R. Hekman (2016) How Does Leader Humility Influence Team Performance? Exploring the Mechanisms of Contagion and Collective Promotion Focus. Academy of Management Journal, 59, 1088-1111. https://doi.org/10.5465/amj.2013.0660

[56] Blaxill, M. and Eckardt, R. (2009) The Invisible Edge: Taking Your Strategy to the Next Level Using Intellectual Property. 1st Edition, Portfolio Hardcover, New York.

[57] Cockburn, I., Henderson, R. and Stern, S. (2017) The Impact of Artificial Intelligence on Innovation. NBER Conference on the Economics of Artificial Intelligence, Toronto.

[58] https://patentimages.storage.googleapis.com/ee/5e/8f/508d2571dd1f1f/US20070130 060A1.pdf

[59] https://patentimages.storage.googleapis.com/89/16/60/b7deee4e85e653/US2006010 0897A1.pdf

[60] Calamel, C. (2013) Le Jazz: Un modèle pour apprendre. De la musique à une construction de soi. Insiders par Charles Calamel. L'Harmattan, Paris.

[61] Devillers, L. (2020) Les robots émotionnels. Santé, surveillance, sexualité...: et l'éthique dans tout ça? Éditions de l'Observatoire/Humensis, Paris.

[62] McEwan, I. (2020) Une Machine comme Moi, Traduit de l'anglais par France Camus-Pichon, GALLIMARD, Machines Like Me and People Like You. Ian McEwan, Éditions Gallimard, pour la traduction française.

[63] Taylor, S.A., et al. (2017) Personalized Multitask Learning for Predicting Tomorrow's Mood, Stress, and Health. IEEE Transactions on Affective Computing, 11, 200-213.

https://affect.media.mit.edu/pdfs/17.TaylorJaques-PredictingTomorrowsMoods.pdf https://doi.org/10.1109/TAFFC.2017.2784832

[64] Goodfellow, I., et al. (2016) Deep Learning. MIT Press, Cambridge, MA. http://www.deeplearningbook.org

[65] Le Cun, Y., Bengio, Y. and Hinton, G. (2015) Deep Learning. Nature, 521, 436-444. https://doi.org/10.1038/nature14539

[66] https://www.ipo.gov.uk/p-challenge-decision-results/o74119.pdf

[67] https://www.uspto.gov/sites/default/files/documents/16524350_22apr2020.pdf

[68] http://artificialinventor.com/

[69] Brosch, et al. (2013) The Impact of Emotion on Perception, Attention, Memory, and Decision-Making. Swiss Medical Weekly, 143, w13786.

[70] Salovey, P. and Mayer, J.D. (1990) Emotional Intelligence. Imagination, Cognition, and Persona, 9, 185-211. https://doi.org/10.2190/DUGG-P24E-52WK-6CDG

[71] Picard, R.W. (1995) Affective Computing. M.I.T Media Laboratory Perceptual Computing Section Technical Report No. 321.

[72] Bouthier, D. (2000) La coordination des décisions individuelles; contribution de 
l'intelligence tactique. Colloque Préparation Olympique "L'évolution de la pensée tactique". INSEP, Noisy le Grand.

[73] Clot, Y. and Faïta, D. (2000) Genre et style en analyse du travail. Concepts et méthodes. Travailler, 4, 7-42.

http://psychanalyse.cnam.fr/revue-travailler/presentation-et-sommaire/numero-4/t heo-

rie-genres-et-styles-en-analyse-du-travail-concepts-et-m-thodes--467242.kjsp?RH= 1304439277304

[74] Bouthier, D., Mouchet, A., Fontayne, P. and Uhlrich, G. (2011) Genre et styles de jeu en rugby: Comparaison de la Coupe du Monde 1999 et 2007. Activités, 8. https://doi.org/10.4000/activites.2469

[75] Deleplace, R. (1979) Rugby de mouvement, rugby total. Edition EPS, Paris.

[76] Deleplace, R. (1983) La recherche sur la spécialisation sportive, l'entraînement, la performance. Actes du colloque "la recherche en STAPS", 19-20 Septembre 1983, Nice, 93-151.

[77] Bouthier, D. (1988) Les conditions cognitives de la formation d'actions sportives collectives. Thèse non publiée, Ecole Pratique des hautes Etudes, Université Paris V, Paris.

[78] Bouthier, D., Barthès, D., David, B. and Gréhaigne, J.F. (1994) Tactical Analysis of Play Combinations in Rugby with Video-Computer; Rationalizing "French Flair". 2nd World Congress of Notational Analysis of Sport, Cardiff, 25-30 November 1994.

[79] Brochard, F., Jeandroz, M. and Villepreux, P. (2007) Rugby: Le jeu, les joueurs, les entraîneurs. Vigot, Paris.

[80] Deleplace, R. (1966) Le rugby, Analyse tactique et pédagogique. Armand Colin, Paris.

[81] Dury, J. (2018) Chap. 4: Rugby de mouvement, rugby total, 1979. In: Deleplace, M., Bouthier, D. and Villepreux, P., Eds., René Deleplace: Du Rugby de mouvement à un projet global pour PEPS et les STAPS, Presses Universitaires du Septentrion, Villeneuve d'Ascq, France, 229-241.

[82] Jeandroz, M. (2018) Chap. 3: La formation au jeu par le jeu-La "revelation" des théories deleplaciennes (3). In: Deleplace, M., Bouthier, D. and Villepreux, P., Eds., René Deleplace: Du Rugby de mouvement à un projet global pour PEPS et les STAPS, Presses Universitaires du Septentrion, Villeneuve d'Ascq, France, 99-100.

[83] Bouthier, D. (1989) Analyse des tâches et de l'activité en sports collectifs; anticipation et décision en rugby. In A. VomHofe (Ed.), Tâches, traitement de P information et comportements en APS, EAP, Issy-les Moulineaux, France, 193-219.

[84] Bouthier, D. (1993) L'approche technologique en STAPS: Représentations et actions en didactique des APS. Diplôme d'Habilitation à Diriger des Recherches en Sciences, spécialité STAPS, non publié, Université Paris-Sud 11, Paris.

[85] Bouthier D. (2014) Iniciacion y perfeccionamiento en los deportescolectivos: Desarrollo de la pertinencia de la toma de decisiones en el juego en relacion con otroselementos de la accion. In: Lopez, V. and Sagartal, J., Eds., El aprendizaje de la acciontactica, Universitat de Girona, Diversitas 76, 99-132.

http://www3.udg.edu/publicacions/vell/electroniques/VI_Jornades_aprendizaje_acc ion_tactica/docs/Diversitas76_BR.pdf

[86] Bouthier, D. (2016) Initiation et perfectionnement en sports collectifs: Développer la pertinence des prises de décision en jeu, en lien avec les autres composantes de 
l'action. Ejournal de la recherche sur Pintervention en éducation physique et sport-eJRIEPS, 38.

[87] Campo, M., Champely, S., Lane, A.M., Rosnet, E., Ferrand, C. and Louvet, B. (2019) Emotions and Performance in Rugby. Journal of Sport and Health Science, 8, 595-600. https://doi.org/10.1016/j.jshs.2016.05.007

[88] Shankland, R. and André, C. (2020) Ces liens qui nous font vivre. Odile Jacob, Paris.

[89] Rebouillat, A. and Curty, M. (2019) Analyse des rapports entre les buts d'accomplissement, l'intérêt individuel et l'intérêt en situation chez les élèves en EPS. Mémoire de Master, Haute École Pédagogique Vaud, Lausanne.

[90] Campo, M. and Djaï, R. (2016) La dimension mentale en rugby: Quels outils au service de l'entraîneur pour former et accompagner les joueurs? De Boeck Supérieur.

[91] Parkinson, B. and Simons, G. (2009) Affecting Others: Social Appraisal and Emotion Contagion in Everyday Decision Making. Personality and Social Psychology Bulletin, 35, 1071-1084. https://doi.org/10.1177/0146167209336611 


\section{Further Reading List}

\section{Generic $A I$}

Bergstein, B. (ed.) (2017) The Artificial Intelligence Issue. MIT Technology Review, 120(6).

Ford, M. (2018) Architects of Intelligence: The Truth about AI from the People Building It. New York: Packet Publishing.

Giles, M. (2018) The GANfather: The Man Who's Given Machines the Gift of Imagination. MIT Technology Review, 121(2), 49-53.

Hoffmann Pham et al. (2018) Data Fusion to Describe and Quantify Search and Rescue Operations in the Mediterranean Sea. 2018 IEEE 5th International Conference on Data Science and Advanced Analytics. Turin: IEEE.

United Nations Global Pulse (2017) Using Machine Learning to Analyse Radio Content in Uganda. Geneva: United Nations.

\section{IP, AI: Moral Rights, Data Privacy, Ethic, Policy, Regulatory}

Ford, M. (2016) The Rise of the Robots: Technology and the Threat of Mass Unemployment. New York: Oneworld Publications.

Barton, J.H. and Maskus, K.E. (2004) Economic Perspectives on a Multilateral Agreement on Open Access to Basic Science and Technology. SCRIPT-ed, 1(3).

Craglia, M. (ed.) (2018) Artificial Intelligence: A European Perspective, EUR 29425 EN. Luxembourg: Publications Office of the European Union.

Preparing for the Future of Artificial Intelligence. (2016) https://info.publicintelligence.net/WhiteHouse-ArtificialIntelligencePreparation s.pdf

\section{$E I$ in $A I$}

Suhara, Y., Xu, Y. and Pentland, A.S. (2017) Deepmood: Forecasting Depressed Mood Based on Self-Reported Histories via Recurrent Neural Networks. Proceedings of the 26th International Conference on World Wide Web.

Thaler, R. and Sunstein, C. (2010) Nudge, Vuibert.

Yasaka, K. and Abe, O. (2018) Deep Learning and Artificial Intelligence in Radiology: Current Applications and Future Directions", PLoS Medicine.

Plutchik R. (1987) Evolutionary Bases of Empathy. In: Eisenberg, N. and Strayer, J. (dir.), Cambridge Studies in Social and Emotional Development. Empathy and Its Development, New York, Cambridge University Press, 38-46.

Kleinginna P.R. and Kleinginna, A.M. (1981) A Categorized List of Emotion Definitions, with Suggestions for a Consensual Definition. Motivation and Emotion, 5(4), 345-359.

Scherer, K.R. (2005) Trends and Development: Research on Emotions. Social Science Information.

Mordvintsev, A., Olah, C. and Tyka, M. (2015) Inceptionism: Going Deeper into Neural Networks, Google Research.

Xu, Y., Lee, A., Wu, W.-L., Liu, X. and Birkholz, P. (2013) Human Vocal Attractiveness as Signaled by Body Size Projection. PloS ONE.

\section{JAZZ-music, education}


Guglielmino, L. (1977) Development of the Self-Directed Learning Readiness Scale. Thèse Non Publiée. Doctoral Dissertation, Athens, University of Georgia.

Ong, W.J. (1982) Orality and Literacy. The Technologizing of the World, Londres, Routledge.

Vulbeau, A., (2006) Alternation, Altération et Métissage: Les Jeux de l'Altérité et de l'Identité. Le Télémaque, $\mathrm{n}^{\circ} 29$, Éducation et Altérité, 160.

\section{AI, historical}

Turing, A. (1950) Computing Machinery and Intelligence, Mind: A Quarterly Review of Philosophy, LIX, 433-460.

McCarthy, J., Minsky, M.L., Rochester, N. and Shannon, C. (1955) A Proposal for the Dartmouth Summer Research Project on Artificial Intelligence.

http://www-formal.stanford.edu/jmc/history/dartmouth/dartmouth.html 